Research Article

\title{
Experimental Investigation on the Behavior of Iron Powder-Reinforced Sand under Electromagnetic Field
}

\author{
Ying Lai, ${ }^{1}$ Bin $\mathrm{Zhu},{ }^{2}$ and Xiangtian $\mathrm{Xu}$ (D) $^{2}$ \\ ${ }^{1}$ Postdoctoral Fellow, MOE Key Laboratory of Soft Soils and Geoenvironmental Engineering, \\ College of Civil Engineering and Architecture, Zhejiang University, 866 Yuhangtang Road, Hangzhou, Zhejiang, China \\ ${ }^{2}$ Professor, MOE Key Laboratory of Soft Soils and Geoenvironmental Engineering, College of Civil Engineering and Architecture, \\ Zhejiang University, 866 Yuhangtang Road, Hangzhou, Zhejiang, China \\ ${ }^{3}$ Associate Professor, Institute of Transportation, Inner Mongolia University, Hohhot 010070, China
}

Correspondence should be addressed to Xiangtian Xu; jtxuxt@imu.edu.cn

Received 21 May 2018; Accepted 30 September 2018; Published 17 October 2018

Academic Editor: Guoqiang Xie

Copyright $(2018$ Ying Lai et al. This is an open access article distributed under the Creative Commons Attribution License, which permits unrestricted use, distribution, and reproduction in any medium, provided the original work is properly cited.

Applications of soil improvement have proliferated in recent years. To date, we have limited studies on the quantitative analyses of the autoadaptive material and specifically to model its stress-strain relationship. This paper explored an autoadaptive material, ironpowdered Ottawa sand, which was temporarily solidified by applying an electromagnetic field. A series of compression triaxial tests were carried out with various relative densities of specimens (60\% and 80\%), in four electromagnetic fields $(0 \mathrm{~A}, 0.5 \mathrm{~A}, 1 \mathrm{~A}$, and $2 \mathrm{~A})$ and under three confining pressures $(103 \mathrm{kPa}, 206 \mathrm{kPa}$, and $310 \mathrm{kPa})$. The test results indicate that the strength of specimens increased while initial stiffness and brittleness reduced by adding iron powder. Moreover, the strength of the specimens increased by increasing the magnitude of the applied electromagnetic field. The behavior of the iron-powdered sand was described by using a revised Duncan-Chang model. The revised model was evaluated by comparing the simulated results with the corresponding test data. The comparison showed that the revised model can better capture the nonlinear stress-strain behavior of the specimens. With the application of the revised Duncan-Chang model, the standard error of the estimate between the experimental and predicted results is lowered down to 0.39 from 4.7. Future research is geared towards practical applications for temporary solidification of soil.

\section{Introduction}

Soil, the most abundant construction material in nature, is entirely inseparable from any constructions and has been used for engineering projects for thousands of years. However, natural soil conditions are not always adequate for required construction. Soil improvements have been intensively studied and successively applied over the past decades. For example, powder, sheets, and rods of polymeric or metal materials [1-6] were placed in soil to increase its yield stress and resistance. These processes of creating reinforced soil are soil strengthening on a macroscale. In comparison, soil stabilization is the process of soil strengthening on a microscale. The matrix of soil can be changed by physically or chemically binding the particles of soil and the reinforced material together [7]. Binding agents include cement or other chemical products [6, 8, 9-11]; binding processes involve heating or freezing $[12,13]$. A possible disadvantage of a reinforced soil is that the strengthening effect depends on the orientation of inclusions. Specifically, a particular direction or surface can provide the maximum strengthening effect. Conversely, a specific direction or surface can weaken the strength of soil [4]. Moreover, the disadvantages of the present available soil stabilization techniques are that improvements in the stress resistance are accompanied by reductions in permeability and ductility.

Despite soil improvement techniques of reinforcement by including polymeric materials and stabilization by adding binding agents, an inventive method, an autoadaptive material has been successfully applied in other engineering disciplines. The autoadaptive materials, such as magnetoand electrostrictive solids and magneto- and electrorheological 
fluids, are the materials that can sense external disturbances and modify their characteristics intentionally to mitigate the effects of the external influence. This improvement characteristic and mitigation property offer an excellent potential application in earthquake engineering. For example, the magnetorheological fluid (MRF) dampers in semiactive vibration devices [14-16] are known to be well suited for suppressing the vibration of structures and systems.

Hryciw and Susila [17] were the first researchers to apply magnetorheological materials in geotechnical engineering. In their study, when a pair of permanent magnets was placed on top and bottom of a specimen, oil-based magnetizable particles transformed from a fluid state into a solid state. As a result, they observed a significant increase in the soil stiffness and strength and a simultaneous decrease in hydraulic conductivity. This innovative method of introducing autoadaptive media causes changes in the properties of soil and overcomes the shortcomings of the soil improvement methods mentioned above.

It is complex to accurately model composite materials consisting of natural (soil) and man-made materials (polymeric, chemical, and binding products). Generally, the constitutive model assumes soil is homogeneous. However, this assumption is not suitable for composite materials with a high degree of anisotropy. In spite of difficulties, some notable achievements have been made in developing a constitutive model and framework for composite materials, including the introduction of Mohr-Coulomb theory into reinforced soil by fiber $[4,18]$, the discrete framework accounting for potential weakness at the soil-inclusion interface [19], and a more complex simulation software developed in [20] for composite materials mixed with chemical products [21].

This research investigates the temporary reinforced effect of iron-powdered Ottawa sand 20-30 under controllable magnitudes of electromagnetic fields. It is interesting to note that the behavior of soil is different from that of metals. Specifically, the strength of soils decreases after peak strength during progressive straining; this phenomenon is termed as "strain softening." In comparison, metal materials exhibit "strain hardening"; an increase in strength occurs during progressive straining. To explore this, it is required to incorporate stress-strain theory with the behavior of Ottawa sand and iron powder under electromagnetic fields. One approach to study the strengthening effect of iron powder temporarily solidified under the electromagnetic fields is to analyze the stress-strain relationship and the strength criterion. Based on the results from triaxial compression tests, we present a stress-strain relationship for iron-powdered sand.

\section{Test Conditions}

The objective of this experiment was to evaluate the effect of different magnitudes of the electromagnetic field on the stress-strain relationship of iron-powdered sand. Undrained compression triaxial tests were performed with a triaxial cell apparatus capable of housing a specimen $3.56 \mathrm{~cm}$ in diameter and $7.11 \mathrm{~cm}$ in height. Axial compression loading is under the strain-controlled mode with a strain limit of $20 \%$ and strain rate of $0.3 \% / \mathrm{min}$. A detailed description of testing materials, sample preparation, and testing procedure is given below.

2.1. Test Materials. The study is undertaken on reconstituted specimens of Ottawa sand 20-30 with various amounts of iron powder. The specific gravity of Ottawa sand 20-30 is $2.65, e_{\max }$ is $0.652, e_{\min }$ is $0.478, D_{50}$ is $0.6, D_{50}$ is 0.76 , and sphericity is 0.85 .

The particle size of iron powder in the specimens needs to be determined by groutability ratio because of the groutability issue of granular soil. The precise groutability ratio is difficult to determine and has been extensively studied because this phenomenon is affected by the soil parameters such as the grain size of the soil and grout which mostly impacts the groutability, the fine contents, the relative density, and the grouting pressure. To determine the grain size of iron powder, we applied the empirical relationship of groutability developed in [22], which involved only the grain size of soil and grout. In Burwell's theory, the groutability index $N$ was introduced to explain the grouting evenness:

$$
N=\frac{D_{15} \text { (soil) }}{d_{85} \text { (grout) }},
$$

where $N$ is the groutability of soil, $D_{15}$ is the diameter through which $15 \%$ of the total soil mass passes, and $d_{85}$ is the diameter through which $85 \%$ of the total grout mass passes. If $N$ calculated by (1) is smaller than 11 , the grout cannot be injected into the soil successfully. If $N$ from (1) is larger than 25, the following equation should be checked additionally:

$$
N=\frac{D_{10} \text { ( soil) }}{d_{95} \text { (grout) }},
$$

where $N$ is the groutability of soil, $D_{10}$ is the diameter through which $10 \%$ of the total soil mass passes, and $d_{95}$ is the diameter through which $95 \%$ of the total grout mass passes. If $N$, calculated by (2), is larger than 11, grouting is possible; otherwise, grout cannot be injected.

Based on these limitations of groutability provided by (1) and (2), we selected the iron powder by its particle size distribution, that is, $d_{85}$ (grout) $<0.0228 \mathrm{~mm}$ and $d_{95}$ (grout) $<0.0472 \mathrm{~mm}$.

2.2. Sample Preparation. The reconstituted specimens were compacted in a three-piece mold with a diameter of $3.56 \mathrm{~cm}$ and height of $7.11 \mathrm{~cm}$. An adjusted method is developed for the sample preparation within a cavity formed by a rubber membrane that lined up with the three-piece split mold. Compaction is achieved by tamping each layer of the specimens by the Harvard Miniature with a circular base attached to its tip. The circular base has a slightly smaller diameter than that of the three-piece split mold, so the shear distortion on the membrane inside the three-piece split mold can be minimized while being pushed downward by the Harvard Miniature.

When preparing the specimens, we choose relative density as a control parameter because it remains constant even when adding iron powder. First, sand is used to 
determine the sample specifications, such as the weight of specimens and how many taps were needed to reach the target relative densities (60\% and $80 \%)$. In order to find the specifications mentioned above, the maximum and minimum void ratios of Ottawa sand are determined according to the methods in $[23,24]$, which are 0.478 and 0.652 , respectively. Then, the void ratio at target relative density can be calculated. Next, we calculated the weight of the sand specimens based on the void ratio at target relative densities ( $60 \%$ and $80 \%)$, the size of the specimen $(3.56 \mathrm{~cm}$ of diameter and $7.11 \mathrm{~cm}$ of height), and the specific gravity of Ottawa sand. The amount of iron powder added to the sand is $10 \%$ of the total specimen weight.

The iron powder content is $10 \%$ by weight of the specimen, and iron powder is premixed with sand before specimen preparation. For the relative density at $60 \%$, the sample is divided into 3 layers and each layer was tapped 3 times. The preliminary trial with Ottawa sand at $80 \%$ relative density using 3 layers yielded a poor distribution of specimens, so to produce more uniform specimens, the number of layers is increased to 5 . At $80 \%$ relative density, the sample is divided into 5 layers and tapped 10 times for each layer. The soil for each layer is weighed, placed in separate containers, and kept sealed until placed into the threepiece split mold. The diameter and height of the compacted specimens are measured after the vacuum is applied and the three-piece mold was removed. The same compaction procedure is followed to obtain a comparable soil property index for both sand specimens and ironpowdered sand.

2.3. Triaxial Test Apparatus and Procedure. The GEOTAC triaxial apparatus made by Trautwein Soil Testing Equipment Company is employed for testing the new material. It consists of GeoJac ${ }^{\mathrm{TM}}$ digital load actuators with a load capacity of $8896.44 \mathrm{~N}$, load frame, and pressure chamber (Figure 1). The test procedure of triaxial compression test followed the procedure in [25-28] except for the following adaptions. First, because the test material is cohesionless as discussed in Sample Preparation, the soil compaction is done in the three-piece split mode which sits on the cell base of the triaxial apparatus and covers the rubber membrane wrapped around the lower platen fixed on the cell base. Then, the rubber membrane is filled with the sand and iron power mixture in layers, and each layer was compacted with Harvard Miniature as described in Sample Preparation. After sample compaction is finished, the magnetic coil is placed upon top of the three-piece mold, and the upper platen attached with the vacuum line goes through the magnetic coil and then is placed on top of the sample (Figure 1 (left)). Next, the upper platen is wrapped by the rubber membrane rolled up from the soil sample, vacuum is applied so that the sample is sealed, and the three-piece split mold is removed so the magnetic coil is around the sample (Figure 1 (middle)). Lastly, carefully place the pressure chamber on the cell base, align with the loading devicee with piston, and leave the electric wires extended from the magnetic coil to the precarved grooves on the cell base, which avoids the wires being pinched by the weight of the

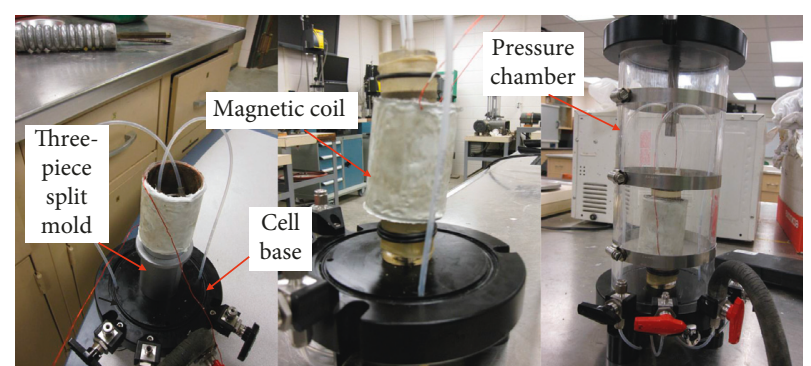

FIgUre 1: Triaxial apparatus with an electromagnetic coil attached.

pressure chamber and the force from applied confining pressure around the soil sample (Figure 1 (right)). These two pieces of wire from the magnetic coil are then connected to the power box capable of providing direct current and being manually controlled. Finally, the magnetic wire around the specimen was powered up before loading.

\section{Experimental Results and Discussion}

3.1. Stress-Strain Relationship. A series of triaxial tests are carried out at two relative densities $(60 \%$ and $80 \%)$ under four currents ( $0 \mathrm{~A}, 0.5 \mathrm{~A}, 1.5 \mathrm{~A}$, and $2 \mathrm{~A}$ ) and three confining pressures $(103 \mathrm{kPa}, 206 \mathrm{kPa}$, and $310 \mathrm{kPa})$. Testing data of deviator stress from 30 triaxial compression tests are collected. The corresponding stress-strain curves under three confining pressures $\sigma_{3}\left(\sigma_{3}=103 \mathrm{kPa}, 206 \mathrm{kPa}\right.$, and $\left.310 \mathrm{kPa}\right)$ and at two relative densities $\left(D_{\mathrm{r}}=60 \%\right.$ and $\left.80 \%\right)$ are shown in Figure 2. Apparently, the lowest peak stress is obtained from the clean sand specimens. The specimens consisting of iron powder and Ottawa sand under the magnetic fields yield similar curves, all of which are slightly above the curve from the clean sand. Therefore, the presence of the iron powder and the electromagnetic field increases the peak stress; adding $10 \%$ iron powder results in an increase of the peak stress, and applying a magnetic field leads to a further increase in peak stress. For instance, if the stress-strain curve is under the same confining pressure and at the same constant relative density, let us say $\sigma_{3}=103 \mathrm{kPa}$ and $D_{\mathrm{r}}=$ $60 \%$, the peak stress increases with an addition of iron content (i.e., from $0 \%$ to $10 \%$ ). As can be seen from Figure 2, the impact of electromagnetic field on the iron-powdered sand on the stress-strain relationship is evident. That is, the peak stress increases with the increase of current imposed through ( $I=0 \mathrm{~A}, 0.5 \mathrm{~A}, 1 \mathrm{~A}$, and $2 \mathrm{~A})$. On the contrary, as can be seen from Figure 2, if one selects a stress-strain curve with the same current (i.e., $I=0.5 \mathrm{~A}$ ) and same relative density (i.e., $D_{\mathrm{r}}=60 \%$ ), the peak stress increases with the increase of confining pressure (i.e., $\sigma_{3}=103 \mathrm{kPa}, 206 \mathrm{kPa}$, and $310 \mathrm{kPa}$ ). Similarly, another set of figures can be drawn for the case of the same confining pressure and the current, say $\sigma_{3}=$ $103 \mathrm{kPa}$ and $I=0.5 \mathrm{~A}$ (Figure 2), and peak stress is found to increase with the increase of relative densities. Note that the strain-softening phenomenon is observed in the stress-strain curves in clean sand specimens and in iron-powdered sand.

The hyperbolic model developed in [29-37] has been applied extensively in geotechnical engineering to model nonlinear behavior of soil and rock. The model can reflect 


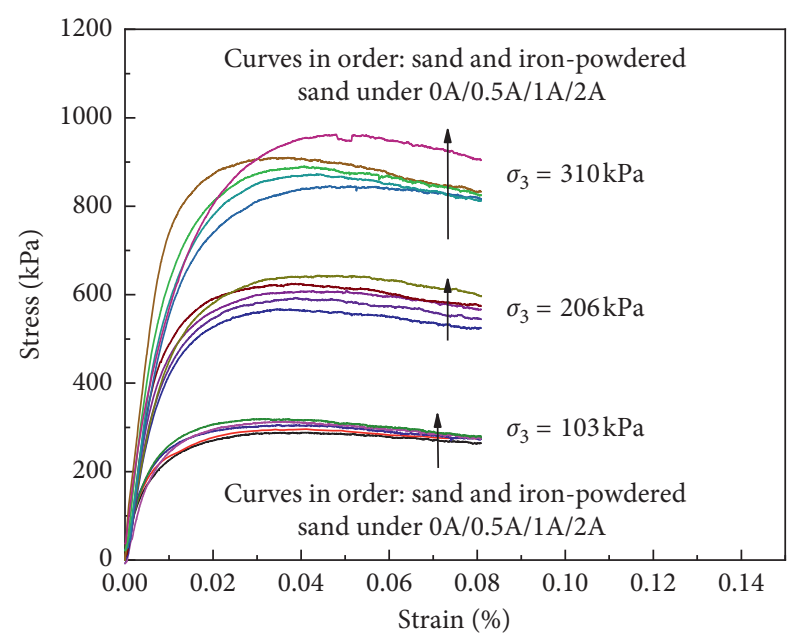

(a)

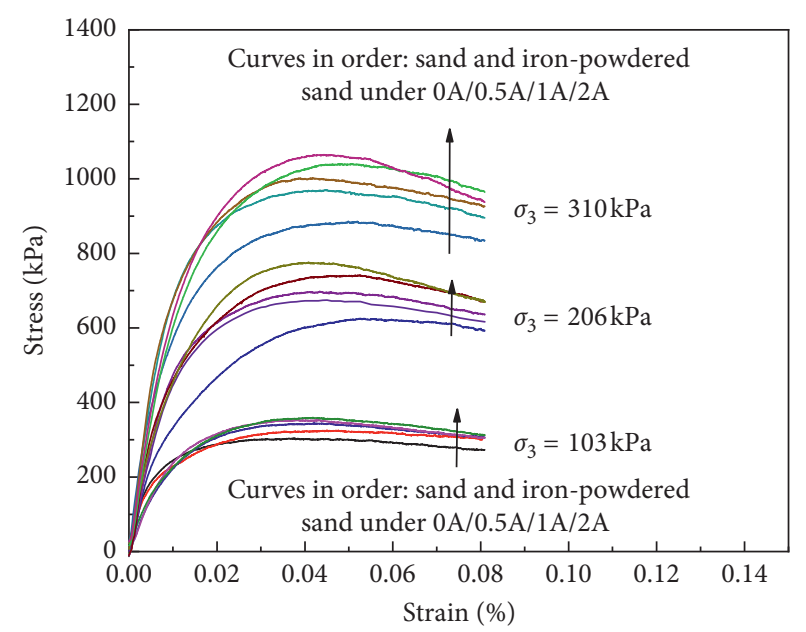

(b)

FIgURE 2: The stress-strain curves of sand specimens with different iron powder contents as well as under different confining pressures and magnitude of the electromagnetic field: specimens at (a) $60 \%$ relative density and (b) $80 \%$ relative density.

the elastic-to-plastic deformation of soil and rock and its parameters have explicit meaning:

$$
\sigma_{1}-\sigma_{3}=\frac{\varepsilon_{1}}{d+e \varepsilon_{1}},
$$

where $\sigma_{1}$ and $\sigma_{3}$ are the major and minor principle stress, respectively; $\varepsilon_{1}$ is the axial strain; and constants $d$ and $e$ are the fitting parameters which can be determined from the conventional compression or the extension triaxial test:

$$
\begin{aligned}
& d=\frac{1}{E_{i}}, \\
& e=\frac{1}{\left(\sigma_{1}-\sigma_{3}\right)_{\mathrm{ult}}} .
\end{aligned}
$$

Generally, the Duncan-Chang model can fit well for the stress-strain relationship with the strain-hardening phenomenon. However, the theoretical basis of the DuncanChang model is an elasticity model based on the generalized incremental Hook's law, which limits its application in geotechnical engineering. Thus, (6) is proposed to describe the soil strain-softening and the prediction of deviator stress from a known axial strain:

$$
\sigma_{1}-\sigma_{3}=\frac{\varepsilon_{1}}{d+e \varepsilon_{1}} f \varepsilon_{1},
$$

where $\sigma_{1}-\sigma_{3}$ is the deviator stress, $\varepsilon_{1}$ is the axial strain, and $d, e$, and $f$ are the fitting parameters.

One more fitting parameter is chosen for the ironpowdered sand so that a better fit can be achieved between the predicted behavior and the strain-softening behavior observed in the triaxial compression tests. To show the capability of the proposed constitutive model by revising the Duncan-Chang model, we compare the observed and the predicted behaviors by the revised Duncan-Chang model and the Duncan-Chang model for each test. For the purpose of demonstration, Figures 3(a) and 3(b) show one set of comparison curves of the confining pressure under $103 \mathrm{kPa}$, the relative density at $60 \%$, and the magnitude of current at $0 \mathrm{~A}$ and $2 \mathrm{~A}$, respectively. As can be seen, the predicted results by the revised model agree perfectly with the observed response. This good agreement suggests that the revised model is capable of accurately predicting the behavior of Ottawa sand and the iron-powdered sand in which strain-softening is dominant.

3.1.1. Prefailure Behavior: Initial Stiffness. The elastic modulus for each testing condition is determined from the corresponding stress-strain curve and summarized in Table 1 and Figure 4. It is evident from Figure 4 that the confining pressure had a significant influence on the elastic modulus. As expected, the elastic modulus was found to increase with increasing confining pressure for both sand and iron-powdered sand under the electromagnetic field. In contrast to the pronounced impact from confining pressure to the elastic modulus, the impact of iron powder inclusion on elastic modulus depends on the relative density of specimens. First, the first three columns in Table 1 show the elastic modulus of specimens at $60 \%$ relative density decreases with the increase of iron content. However, for specimens at $80 \%$ relative density shown in the first three columns in Table 1 , the elastic modulus is relatively independent of the iron content. Second, as shown in Figure 4(a) and Table 1, the elastic modulus increases with the increase of magnitude of current imposed through for specimens at $60 \%$ relative density under any confining pressure and magnitude of the electromagnetic field. However, at $80 \%$ relative density (Figure 4(b) and Table 1), the elastic modulus increases with the increase of magnitude of the electromagnetic field under any confining pressure except $310 \mathrm{kPa}$. When investigating the effect of relative density on elastic modulus, one can pick two data points from Figure 4 with the same testing condition (confining pressure and the magnitude of electromagnetic field) and find the specimens with higher relative 


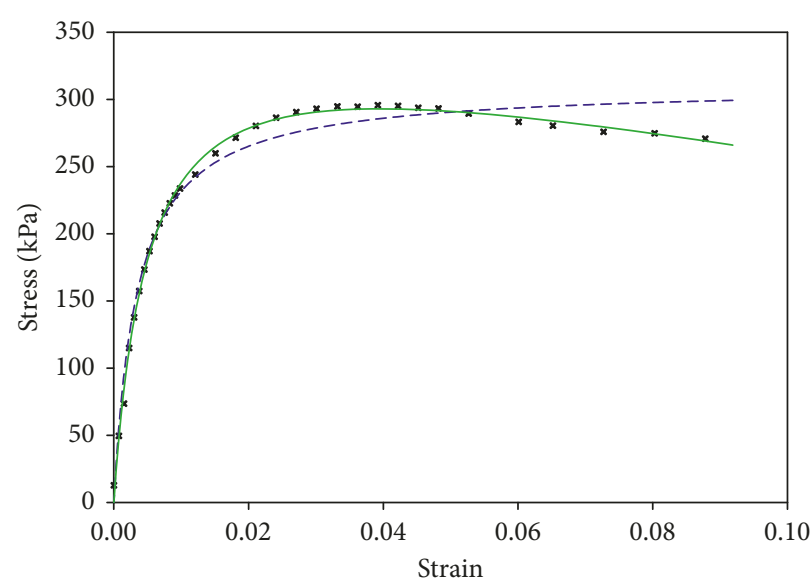

* Experimental results

- -- Simulated based on Duncan-Chang model

— Revised model

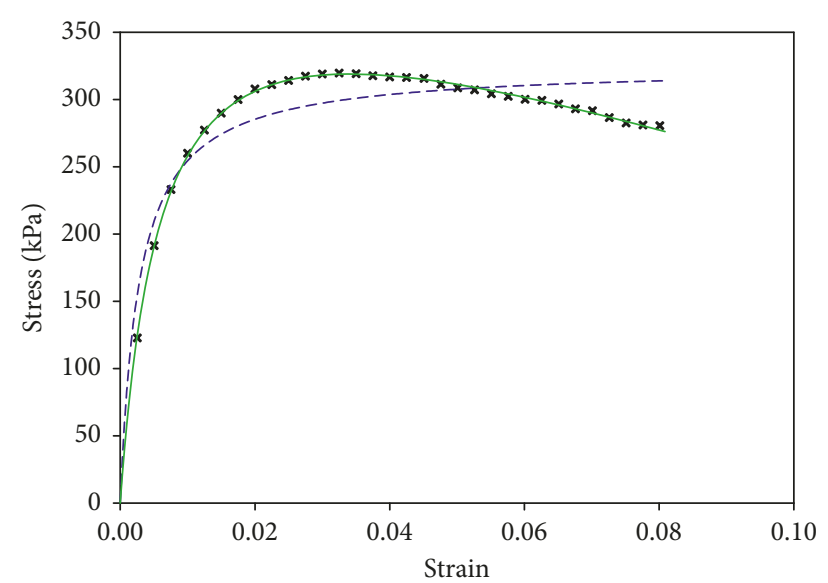

* Experimental results

--- Simulated based on Duncan-Chang model

_ Revised model

(a)

(b)

Figure 3: Comparison between the Duncan-Chang model and the revised model: (a) iron-powdered sand at $60 \%$ relative density and under $103 \mathrm{kPa}$ confining pressure; (b) iron-powdered sand at 60\% relative density and under $2 \mathrm{~A}$ current and $103 \mathrm{kPa}$ confining pressure.

TABLE 1: Elastic modulus.

\begin{tabular}{lccccc}
\hline$\sigma_{3}(\mathrm{kPa})$ & $\begin{array}{c}\text { Sand } \\
(\mathrm{kPa})\end{array}$ & $\begin{array}{c}\text { Iron-powdered sand } \\
(\mathrm{kPa})\end{array}$ & $\begin{array}{c}\text { Iron-powdered sand under } \\
0.5 \mathrm{~A}(\mathrm{kPa})\end{array}$ & $\begin{array}{c}\text { Iron-powdered sand under } \\
1 \mathrm{~A}(\mathrm{kPa})\end{array}$ & $\begin{array}{c}\text { Iron-powdered sand under } \\
2 \mathrm{APPa})\end{array}$ \\
\hline $\begin{array}{l}\text { Relative density at } 60 \% \\
103\end{array}$ & & & & 31533.01 & 38477.60 \\
20409.68 & 16464.47 & 22983.93 & 50010.53 & 56840.49 \\
310 & 42855.95 & 33820.75 & 42773.88 & 65811.87 & 76135.43 \\
\hline Relative density at $80 \%$ & & 62280.16 & & 41039.19 \\
103 & 35069.21 & 33076.31 & & 37699.62 & 68462.87 \\
206 & 48027.40 & 48448.40 & 34522.15 & 65218.19 & 70504.34 \\
310 & 77618.35 & 80643.42 & 54550.36 & 66799.12 & \\
\hline
\end{tabular}

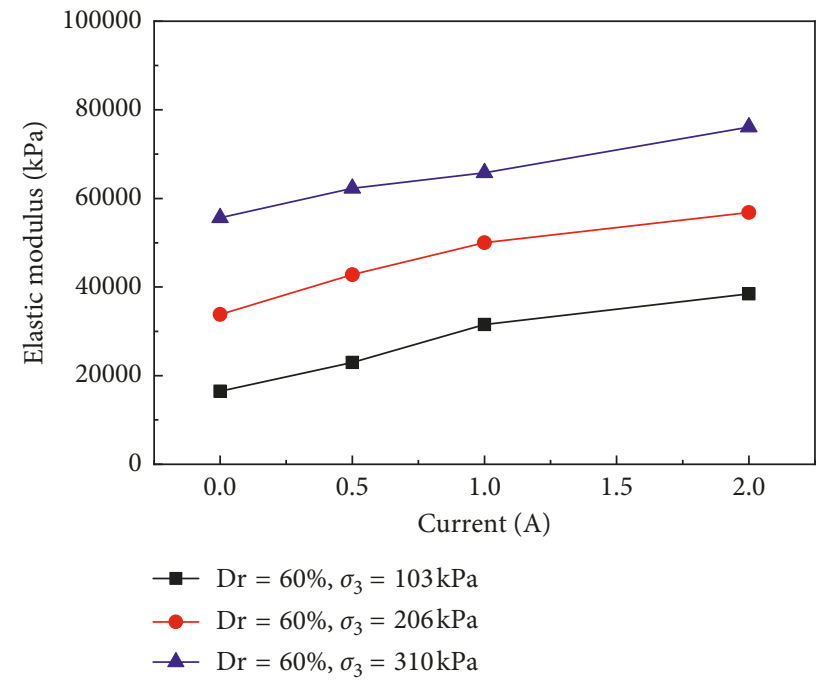

(a)

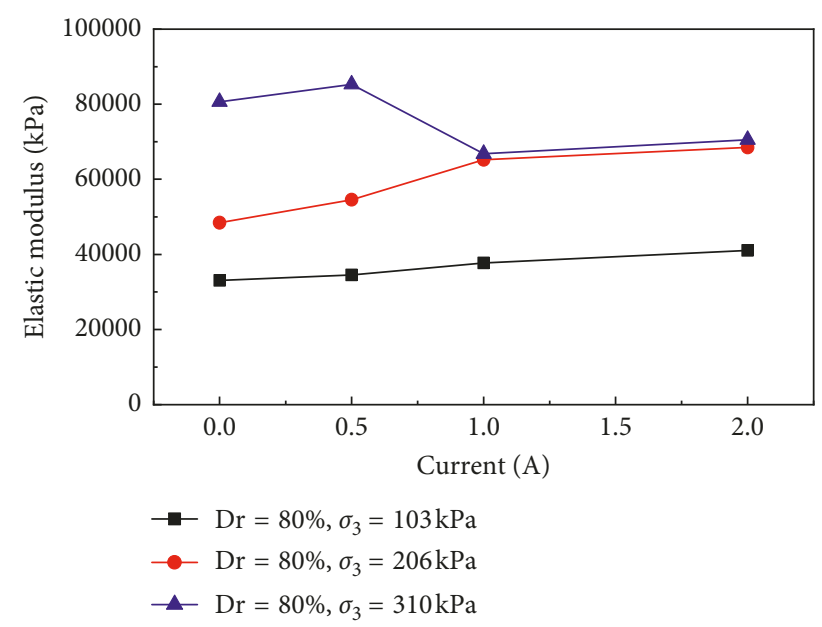

(b)

Figure 4: Elastic modulus: iron-powdered sand at (a) $60 \%$ relative density and (b) $80 \%$ relative density under different magnitude of the electromagnetic field. 
density which presents greater stiffness at the initial loading stage. In parallel, the effect of relative density as related to elastic modulus is captured from Figure 4 that the elastic modulus is moderately increased with increasing relative density.

From the above discussion, it concludes that the elastic modulus is a function of relative density, confining pressure, iron content, and the magnitude of electromagnetic field. It also implies that the ability of specimens to resist deformation at the initial loading stage arises from void ratio (which depends on relative density, confining pressure, and iron content) and the internal friction between soil particles (which depends on iron content and the magnitude of electromagnetic field). The confining pressure and relative density determine the initial void ratio of specimens with pure sand, and additionally, iron content and the magnitude of electromagnetic field influence the initial void ratio of the iron powder-reinforced specimens. The internal resistance for pure sand specimens is provided by interlock between sand particles and frictional forces from unsmooth surfaces. In comparison, the internal resistance for iron powderreinforced specimens is additionally governed by the iron powder content and the magnitude of electromagnetic field. As discussed in Section 2.2, the iron content is $10 \%$ by weight of the sample, which implies that the specimen with relative density at $60 \%$ contains less iron powder compared with the specimen with relative density at $80 \%$. At the sample preparation stage, we observe that the iron powder coating is around the sand particles. Therefore, at a relative density of $60 \%$, most of the iron powder was coated around sand particles and little powder is filled into voids between particles to densify the specimens. Hence, the coating by iron powder reduced the internal friction of iron powderreinforced specimens, and the elastic modulus decreased if iron powder is added (as shown in Figure 4(a)). However, compared with specimens with a relative density of $60 \%$, specimens at $80 \%$ relative density contain smaller voids and more iron powder (iron powder is still $10 \%$ by weight of the specimen but is with a heavier weight since the specimen is heavier at higher relative density). Therefore, except coating around sand particles, iron powder filled most of the voids which densifies iron powder-reinforced specimens. Moreover, the densification effect from filling voids by iron powder dominates over the coating effect around particles; as a result, iron powder inclusion slightly increases the elastic modulus of specimens. When the electromagnetic field is applied by powering up the coil around the specimen, the elastic modulus generally increases with the increase of magnitude of current (Figure 4) except when the relative density is $80 \%$, confining pressure is $310 \mathrm{kPa}$, and current is above 1 A. Figure 4(a) shows that the elastic modulus of $60 \%$ relative density sample increases with the current amplitude, which is reasonable since a higher magnitude of electromagnetic field is generated to strengthen the specimens and increase the internal resistance. However, at $80 \%$ relative density and under $310 \mathrm{kPa}$ confining pressure, the elastic modulus has no continuous increase with the increase of magnitude of current. This is rational since the coating sand particles are compacted at a denser degree, which makes it easier for coating sand particles slide over each other with a higher driving force on the iron powder particles from the electromagnetic field. Therefore, the elastic modulus decreases with the increase of current amplitude at a higher confining pressure.

3.1.2. Peak Stress. The most impressive advantage of iron powder inclusion together with electromagnetic field reinforcement is the improvement of peak strength. The peak stress from each test is summarized in Table 2. An absolute measure to quantify this improvement is provided by strength ratio defined as the ratio of peak deviator stress of the reinforced specimen to that of the unreinforced specimen for similar conditions. The effects from the magnitude of electromagnetic field, confining pressure, and relative density on the improvement of peak stress are presented in Figure 5. As expected, the magnitude of the electromagnetic field has positive impact on strength improvement. Additionally, for all reinforced specimens, the improvement of strength is more obvious for specimens under $103 \mathrm{kPa}$ to $206 \mathrm{kPa}$ than those under $310 \mathrm{kPa}$, and similar trends are observed at all relative densities. This indicates that the benefit of iron powder reinforcement as well as the electromagnetic field is more significant at medium to low confining pressure. It is reasonable since the specimens under high confining pressure is already stiff and the effectiveness of iron powder together with the electromagnetic field is less remarkable. The strength improvement is more pronounced at $80 \%$ relative density. It verifies that iron powder coating around sand particles at $60 \%$ relative density reduces surface friction between sand particles in the microscopic view and reduces strength overall.

From the discussion above, we conclude that peak stress is a function of four variables: iron content, confining pressure, relative density, and current. The contribution of each variable could be evaluated by regressing the fitting parameters with the test variables. The fitting parameters $d$, $e$, and $f$ (shown in Table 3 ) are assumed to be a function of the testing variables, that is, relative density, confining pressure, and current. The function is expressed as follows:

$$
\begin{aligned}
& d=\left(a_{1}\left(\sigma_{3}\right)^{a_{2}}\right) \times\left(1+m_{d} I_{i}+n_{d} I_{i}^{2}+l_{d} I_{i}^{3}\right), \\
& e=\left(b_{1} \sigma_{3}^{2}+b_{2} \sigma_{3}+b_{3}\right) \times\left(1+m_{e} I_{i}+n_{e} I_{i}^{2}+l_{e} I_{i}^{3}\right), \\
& f=\left(c_{1} \sigma_{3}^{2}-c_{2} \sigma_{3}-c_{3}\right) \times\left(1+m_{f} I_{i}+n_{f} I_{i}^{2}+l_{f} I_{i}^{3}\right) .
\end{aligned}
$$

Next, the determination of the function is as follows.

Taking the determination of the parameter $d$ at $60 \%$ relative density as an example,

$$
d=F\left(\sigma_{3}, I, D_{\mathrm{r}}, \mathrm{Fe} \%\right)
$$

which can be written as a piecewise function:

$$
d= \begin{cases}f_{0}\left(\sigma_{3}\right), & \text { if } \mathrm{Fe} \%=0, \\ f_{1}\left(\sigma_{3}\right) \times f_{2}\left(I_{i}\right), & \text { if } \mathrm{Fe} \%>0 .\end{cases}
$$

First, $f_{0}\left(\sigma_{3}\right)$ is obtained by regressing the fitting parameter $d$ and confining pressure values: 
TABle 2: Peak stress.

\begin{tabular}{|c|c|c|c|c|c|}
\hline$\sigma_{3}(\mathrm{kPa})$ & Sand $(\mathrm{kPa})$ & $\begin{array}{l}\text { Iron-powdered } \\
\text { sand }(\mathrm{kPa})\end{array}$ & $\begin{array}{l}\text { Iron-powdered sand } \\
\text { under } 0.5 \mathrm{~A}(\mathrm{kPa})\end{array}$ & $\begin{array}{l}\text { Iron-powdered sand } \\
\text { under } 1 \mathrm{~A}(\mathrm{kPa})\end{array}$ & $\begin{array}{c}\text { Iron-powdered sand } \\
\text { under } 2 \mathrm{~A}(\mathrm{kPa})\end{array}$ \\
\hline \multicolumn{6}{|c|}{ Relative density at $60 \%$} \\
\hline 103 & 287.82 & 298.78 & 307.69 & 312.49 & 318.65 \\
\hline 206 & 580.43 & 596.19 & 612.23 & 622.92 & 641.42 \\
\hline 310 & 842.89 & 870.30 & 890.86 & 904.56 & 938.83 \\
\hline \multicolumn{6}{|c|}{ Relative density at $80 \%$} \\
\hline 103 & 306.25 & 344.63 & 364.64 & 370.05 & 377.42 \\
\hline 206 & 627.93 & 673.69 & 692.13 & 746.95 & 774.36 \\
\hline 310 & 871.28 & 952.53 & 986.80 & 1027.91 & 1041.62 \\
\hline
\end{tabular}

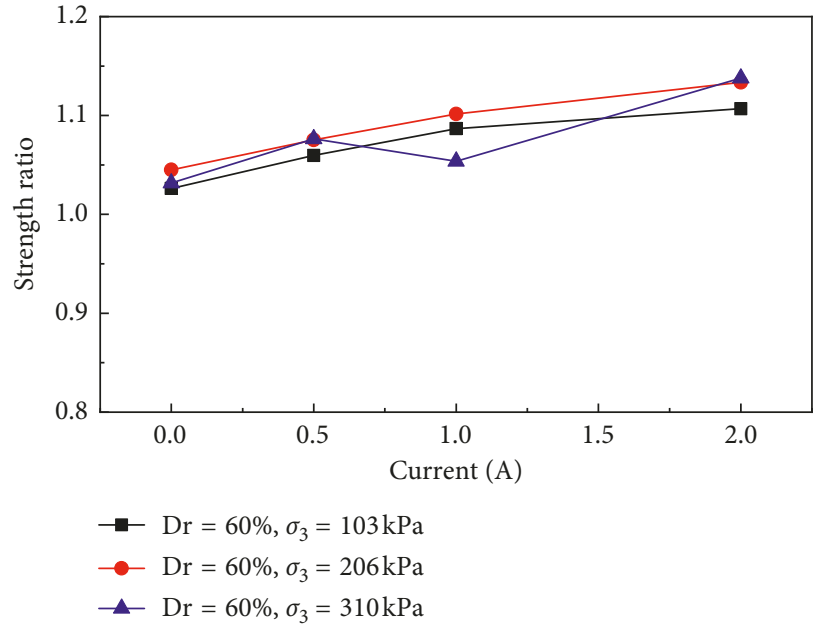

(a)

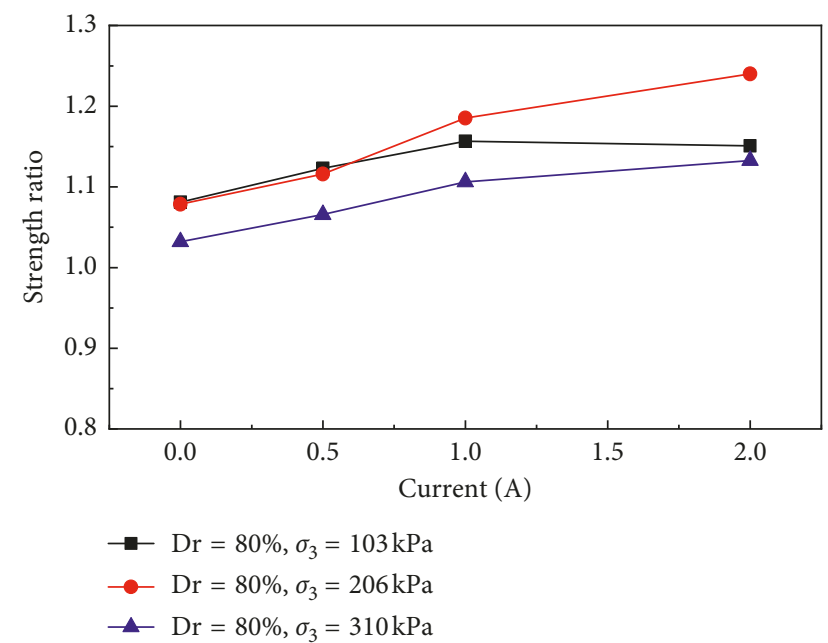

(b)

FIGURE 5: Variation of strength ratio with the magnitude of the electromagnetic field for different confining pressures and relative densities: specimens at (a) $60 \%$ relative density and (b) $80 \%$ relative density.

TABle 3: The fitting parameter.

\begin{tabular}{|c|c|c|c|c|c|}
\hline$\sigma_{3}(\mathrm{kPa})$ & Sand $(\mathrm{kPa})$ & $\begin{array}{l}\text { Iron-powdered } \\
\text { sand }(\mathrm{kPa})\end{array}$ & $\begin{array}{c}\text { Iron-powdered sand } \\
\text { under } 0.5 \mathrm{~A}(\mathrm{kPa})\end{array}$ & $\begin{array}{l}\text { Iron-powdered sand } \\
\text { under } 1 \mathrm{~A}(\mathrm{kPa})\end{array}$ & $\begin{array}{c}\text { Iron-powdered sand } \\
\text { under } 2 \mathrm{~A}(\mathrm{kPa})\end{array}$ \\
\hline \multicolumn{6}{|c|}{$d$ at $60 \%$ relative density } \\
\hline 103 & 61.77 & 54.18 & 59.03 & 67.01 & 64.64 \\
\hline 206 & 138.25 & 130.01 & 148.96 & 129.76 & 159.71 \\
\hline 310 & 189.05 & 205.85 & 216.72 & 196.42 & 243.50 \\
\hline \multicolumn{6}{|c|}{$d$ at $80 \%$ relative density } \\
\hline 103 & 58.96 & 67.91 & 86.09 & 91.19 & 93.30 \\
\hline 206 & 169.67 & 171.83 & 168.42 & 190.48 & 237.16 \\
\hline 310 & 194.13 & 219.43 & 239.95 & 286.44 & 309.82 \\
\hline \multicolumn{6}{|c|}{ e at $60 \%$ relative density } \\
\hline 103 & 0.0089 & 0.0051 & 0.0055 & 0.008 & 0.0062 \\
\hline 206 & 0.0127 & 0.0095 & 0.0140 & 0.0077 & 0.0144 \\
\hline 310 & 0.0124 & 0.0125 & 0.0112 & 0.0102 & 0.0163 \\
\hline \multicolumn{6}{|c|}{ e at $80 \%$ relative density } \\
\hline 103 & 0.030 & 0.010 & 0.014 & 0.0138 & 0.015 \\
\hline 206 & 0.020 & 0.015 & 0.013 & 0.016 & 0.02 \\
\hline 310 & 0.010 & 0.0111 & 0.012 & 0.019 & 0.019 \\
\hline \multicolumn{6}{|c|}{ fat $60 \%$ relative density } \\
\hline 103 & -212.69 & -138.50 & -195.51 & -263.63 & -246.68 \\
\hline 206 & -546.91 & -469.56 & -537.34 & -445.84 & -591.54 \\
\hline 310 & -556.91 & -750.52 & -881.63 & -679.92 & -882.90 \\
\hline \multicolumn{6}{|c|}{ f at $80 \%$ relative density } \\
\hline 103 & -556.90 & -207.54 & -368.15 & -419.67 & -411.32 \\
\hline 206 & -577.91 & -689.71 & -650.82 & -758.04 & -1153.73 \\
\hline 310 & -590.40 & -770.31 & -831.82 & -1116.84 & -1399.20 \\
\hline
\end{tabular}




$$
f_{0}\left(\sigma_{3}\right)=3.8504 \sigma_{3}^{1.0337}, \quad \text { if } \mathrm{Fe} \%=0 .
$$

Second, in order to determine $f_{1}\left(\sigma_{3}\right)$, by regressing data from column 1 and column 3 in Table 3, we obtain

$$
d=2.006 \sigma_{3}^{1.2202} \text {. }
$$

$f_{2}\left(I_{i}\right)$ can be expressed as follows:

$$
\begin{aligned}
f_{2}\left(I_{i}\right) & =1+m I_{i}-n I_{i}^{2}+l I_{i}^{3}, \\
\Pi & =\sum_{i=1}^{j}\left[f_{2}\left(I_{i}\right)-y_{i}\right]^{2}=\sum_{i=1}^{j}\left[1+m I_{i}+n I_{i}^{2}+l I_{i}^{3}-y_{i}\right]^{2} .
\end{aligned}
$$

In order to obtain $m, n$, and $l,(15)$ is differentiated:

$$
\begin{aligned}
& \frac{\partial \Pi}{\partial m}=2\left[\mathrm{~m} \sum_{i=1}^{j} I_{i}^{2}+\mathrm{n} \sum_{i=1}^{j} I_{i}^{3}+1 \sum_{i=1}^{j} I_{i}^{4}-\sum_{i=1}^{j} I_{i} y_{i}+\sum_{i=1}^{j} I_{i}\right]=0, \\
& \frac{\partial \Pi}{\partial n}=2\left[\mathrm{~m} \sum_{i=1}^{j} I_{i}^{3}+\mathrm{n} \sum_{i=1}^{j} I_{i}^{4}+1 \sum_{i=1}^{j} I_{i}^{5}-\sum_{i=1}^{j} I_{i}^{2} y_{i}+\sum_{i=1}^{j} I_{i}^{2}\right]=0, \\
& \frac{\partial \Pi}{\partial l}=2\left[\mathrm{~m} \sum_{i=1}^{j} I_{i}^{4}+\mathrm{n} \sum_{i=1}^{j} I_{i}^{5}+1 \sum_{i=1}^{j} I_{i}^{6}-\sum_{i=1}^{j} I_{i}^{3} y_{i}+\sum_{i=1}^{j} I_{i}^{3}\right]=0,
\end{aligned}
$$$$
m=\frac{1}{\Delta} \cdot\left|\begin{array}{ll}
\left(\sum_{i=1}^{j} I_{i} y_{i}-\sum_{i=1}^{j} I_{i}\right) \sum_{i=1}^{j} I_{i}^{3} & \sum_{i=1}^{j} I_{i}^{4} \\
\left(\sum_{i=1}^{j} I_{i}^{2} y_{i}-\sum_{i=1}^{j} I_{i}^{2}\right) & \sum_{i=1}^{j} I_{i}^{4} \sum_{i=1}^{j} I_{i}^{5} \\
\left(\sum_{i=1}^{j} I_{i}^{3} y_{i}-\sum_{i=1}^{j} I_{i}^{3}\right) & \sum_{i=1}^{j} I_{i}^{5} \sum_{i=1}^{j} I_{i}^{6}
\end{array}\right|,
$$$$
n=\frac{1}{\Delta} \cdot\left|\begin{array}{ll}
\sum_{i=1}^{j} I_{i}^{2} & \left(\sum_{i=1}^{j} I_{i} y_{i}-\sum_{i=1}^{j} I_{i}\right) \sum_{i=1}^{j} I_{i}^{4} \\
\sum_{i=1}^{j} I_{i}^{3} & \left(\sum_{i=1}^{j} I_{i}^{2} y_{i}-\sum_{i=1}^{j} I_{i}^{2}\right) \sum_{i=1}^{j} I_{i}^{5} \\
\sum_{i=1}^{j} I_{i}^{4} & \left(\sum_{i=1}^{j} I_{i}^{3} y_{i}-\sum_{i=1}^{j} I_{i}^{3}\right) \sum_{i=1}^{j} I_{i}^{6}
\end{array}\right|,
$$$$
l=\frac{1}{\Delta} \cdot\left|\begin{array}{ccc}
\sum_{i=1}^{j} I_{i}^{2} & \sum_{i=1}^{j} I_{i}^{3} & \left(\sum_{i=1}^{j} I_{i} y_{i}-\sum_{i=1}^{j} I_{i}\right) \\
\sum_{i=1}^{j} I_{i}^{3} & \sum_{i=1}^{j} I_{i}^{4} & \left(\sum_{i=1}^{j} I_{i}^{2} y_{i}-\sum_{i=1}^{j} I_{i}^{2}\right) \\
\sum_{i=1}^{j} I_{i}^{4} & \sum_{i=1}^{j} I_{i}^{5} & \left(\sum_{i=1}^{j} I_{i}^{3} y_{i}-\sum_{i=1}^{j} I_{i}^{3}\right)
\end{array}\right|,
$$

where

$$
\Delta=\left|\begin{array}{ccc}
\sum_{i=1}^{j} I_{i}^{2} & \sum_{i=1}^{j} I_{i}^{3} & \sum_{i=1}^{j} I_{i}^{4} \\
\sum_{i=1}^{j} I_{i}^{3} & \sum_{i=1}^{j} I_{i}^{4} & \sum_{i=1}^{j} I_{i}^{5} \\
\sum_{i=1}^{j} I_{i}^{4} & \sum_{i=1}^{j} I_{i}^{5} & \sum_{i=1}^{j} I_{i}^{6}
\end{array}\right| .
$$

Based on the experimental results, we obtain the following parameters: $m=0.30, n=-0.46, l=0.17$, and $j=12$, in this study.

Thus,

$$
\begin{aligned}
& f_{2}\left(I_{i}\right)=1+0.30 I_{i}-0.46 I_{i}^{2}+0.17 I_{i}^{3}, \\
& d= \begin{cases}3.85 \sigma_{3}^{1.0337}, & \text { if } \mathrm{Fe} \%=0, \\
\left(2.006 \sigma_{3}^{1.2202}\right) & \\
\times\left(1+0.30 I_{i}-0.46 I_{i}^{2}+0.17 I_{i}^{3}\right), & \text { if } \mathrm{Fe} \%>0 .\end{cases}
\end{aligned}
$$

The same process is applied to relate fitting parameters $e$ and $f$ at different test conditions.

At relative density $60 \%$, the following can be obtained:

If no magnetic field is applied, then we have the following equations:

$$
\begin{aligned}
& d=3.85 \sigma_{3}^{1.0337} \\
& e=\left(-9 E-06 \sigma_{3}^{2}+0.0007 \sigma_{3}+0.001\right) \\
& f=\left(0.72 \sigma_{3}^{2}-54.71 \sigma_{3}+445.77\right)
\end{aligned}
$$

If a magnetic field is applied, we can obtain

$$
\begin{aligned}
d= & \left(2.006 \sigma_{3}^{1.2202}\right) \times\left(1+0.30 I_{i}-0.46 I_{i}^{2}+0.17 I_{i}^{3}\right), \\
e= & \left(-3 E-06 \sigma_{3}^{2}+0.0004 \sigma_{3}-0.0007\right) \\
& \times\left(1-0.21 I_{i}-0.14 I_{i}^{2}+0.13 I_{i}^{3}\right), \\
f= & \left(0.11 \sigma_{3}^{2}-27.08 \sigma_{3}+242.64\right) \\
& \times\left(1+0.72 I_{i}-0.97 I_{i}^{2}+0.34 I_{i}^{3}\right) .
\end{aligned}
$$

At $80 \%$ relative density, the following can be obtained: If no magnetic field is applied,

$$
\begin{aligned}
& d=4.41 \sigma_{3}^{1.0398}, \\
& e=\left(-5 E-05 \sigma_{3}^{2}+0.003 \sigma_{3}-0.03\right), \\
& f=\left(0.71 \sigma_{3}^{2}-53.81 \sigma_{3}+400.71\right),
\end{aligned}
$$

If a magnetic field is applied,

$$
\begin{aligned}
d= & \left(3.64 \sigma_{3}^{1.0969}\right) \times\left(1+0.316 I_{i}+0.076 I_{i}^{2}-0.057 I_{i}^{3}\right), \\
e= & \left(-2 E-05 \sigma_{3}^{2}+0.001 \sigma_{3}-0.0042\right) \\
& \times\left(1-1.200 I_{i}+2.154 I_{i}^{2}-0.746 I_{i}^{3}\right) \\
f= & \left(0.892 \sigma_{3}^{2}-72.303 \sigma_{3}+676.21\right) \\
& \times\left(1+0.720 I_{i}-0.066 I_{i}^{2}-0.021 I_{i}^{3}\right) .
\end{aligned}
$$


3.1.3. Postpeak Behavior. The postpeak behavior of the iron powder-reinforced autoadaptive material was examined in terms of brittleness $\left(I_{\mathrm{B}}\right)$ and energy absorption capacity (EAC).

(1) Brittleness. We can observe from stress-strain curves in Figure 2 that the residual strength of autoadaptive specimens remains higher than that of unreinforced specimens after peak strength, which suggests that the autoadaptive material would sustain greater load even at a larger deformation compared to unreinforced sand. To quantify this behavior, the brittleness index $\left(I_{\mathrm{B}}\right)$ defined in [38] is applied:

$$
I_{\mathrm{B}}=\frac{\sigma_{d, \text { peak }}}{\sigma_{d, \mathrm{res}}}-1,
$$

where $\sigma_{d \text {,peak }}$ is the peak deviator stress and $\sigma_{d \text {,res }}$ is the residual deviator stress of the specimen. The ductility behavior increases as $I_{\mathrm{B}}$ decreases towards zero.

As expected, the brittleness is found to be greater for specimens with higher relative density (Figure 6 and Table 4). This implies that the relative density dominates the ductility behavior of sand and unreinforced sand over the magnitude of electromagnetic field. It is interesting to note that the inclusion of iron powder improved ductility of specimens; however, the existence of electromagnetic field decreased ductility (Figure 6). The peak and residual stress have been improved (Figure 2) by the inclusion of iron powder but with a greater improvement of residual stress; as a result, the brittleness index for the iron-powdered sand was reduced. This validates again that iron powder coating around the soil particles, which made soil particles easier to rearrange in the microscopic view and makes specimens easier to deform even at a relatively larger strain. Applying the electromagnetic field can strengthen the specimens and decreases the ductility of iron powder-reinforced specimens (Figure 6).

(2) Energy Absorption Capacity. As defined in [39], the energy absorption capacity is introduced to describe toughness of fiber-reinforced concrete under flexural loading condition. The energy absorption capacity (EAC) is defined by the area under the stress-strain curve up to a reference strain ( $8 \%$ is selected in this study).

The EAC of the autoadaptive specimen is from energy dissipated from the soil matrix deformation $(\mathrm{EAC})_{\mathrm{s}}$ and the energy dissipated through iron powder particles movement driven by electromagnetic force $(E A C)_{i}$. Hence, the total energy absorption capacity (EAC) of the autoadaptive material can be expressed as follows:

$$
\mathrm{EAC}=(\mathrm{EAC})_{\mathrm{s}}+(\mathrm{EAC})_{\mathrm{i}}
$$

Table 5 and Figure 7 present the energy absorption capacity of each specimen. Figure 7 demonstrates the impact of the magnitude of electromagnetic field and confining pressure on energy absorption improvement. The general pattern interpreted in Table 5 and Figure 7 is quite similar to that previously demonstrated in Table 2 for the peak stress response. All of the testing factors noticeably affected the energy absorption capacity positively of both sand and iron-powdered sand under the electromagnetic field. As shown in the first three columns in Table 5, the effect of inclusion of iron powder is found to be more pronounced for the specimens under higher confining pressures. Figures 7(a) and 7(b) show the increase in magnitude of the electromagnetic field leads to a higher improvement of energy absorption capacity. If one picks one data point from Figures $7(\mathrm{a})$ and $7(\mathrm{~b})$ for the same testing condition (the confining pressure and magnitude of current) except relative density, it can be noticed that the relative density has positive effect on the energy absorption.

Alternatively, the energy absorption capacity can also be evaluated by normalizing the EAC over the entire stressstrain curve, which is expressed as $\left[(\mathrm{EAC})_{\varepsilon} /(\mathrm{EAC})_{\varepsilon_{\mathrm{ref}}}\right]$. The $(\mathrm{EAC})_{\mathcal{\varepsilon}}$ represents the area up to any axial strain $\mathcal{\varepsilon}$ on the stress-strain curve, and $(\mathrm{EAC})_{\varepsilon_{\text {ref }}}$ is the area to a reference strain $\varepsilon_{\text {ref }}$ ( $8 \%$ in this study). To make a distinction of effect from different variables (relative density, magnitude of the electromagnetic field, and confining pressure) on soil behavior, Figures 7 (c) to 7 (e) show three examples of normalized energy absorption against the axial strain with variation of parameters in each plot. First, the normalized energy absorption for iron powder-reinforced sand increases with the axial strain at an almost constant rate (Figure 7 (c) to Figure $7(\mathrm{e}))$. The increase of relative density, confining pressure, and the magnitude of electromagnetic field leads to a lower energy absorption rate, which indicates soil behaves predominantly brittle. This agrees well with the deviator stress-strain curves shown in Figure 2 and brittleness index shown in Figure 6.

3.2. Shear Strength Parameters. To investigate the influence of the electromagnetic field on the friction angle and cohesive coefficient, we plot the Mohr-Coulomb failure envelopes at different test conditions. To precisely assess the friction angle and cohesive coefficient, we employ the method of linearizing triaxial test failure envelopes [40]. Generally, the friction angle and the cohesive coefficient are obtained by drawing a tangent line to a series of Mohr's circles. However, it is easier and more accurate to regress on the scattered points from the stress path than to draw a tangent line to a series of circles. Additionally, linear regression on the scattered points gives the statistical evaluation of the data fitting. Handy [40] pointed out that variability biases exist either by best fit by eye or by regression of the $p$ - $q$ diagram from the triaxial test data, which leads to an overestimation of the friction angle. The reason for these biases is that the variability is $45^{\circ}$ to the $y$-axis if lateral stress $\sigma_{3}$ is constant. As can be seen in the MohrCoulomb envelope equation,

$$
\tau=c+\sigma \times \tan \alpha .
$$

The independent variable is $\sigma$, and it is assumed that the test variability is parallel to the $y$-axis. However, as shown in Figure 8, the variability of $\tau$ is not parallel to the $y$-axis, and it is a line inclined with the $y$-axis. This variability bias leads to the overestimation of the friction angle and will be involved when regressing $p$ - $q$ data points on the $p$ - $q$ plane. 


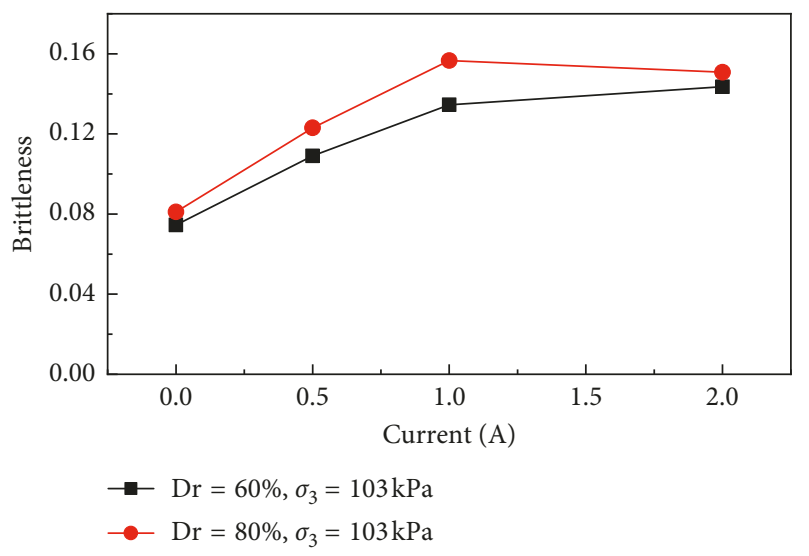

(a)

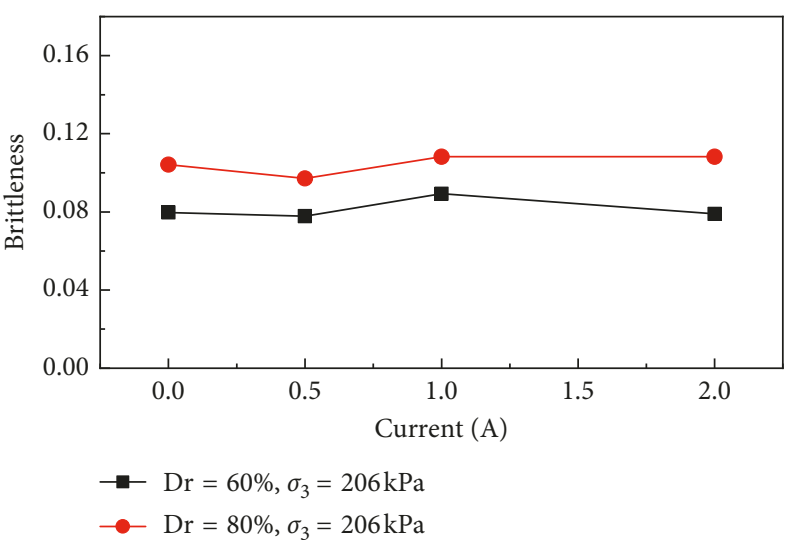

(b)

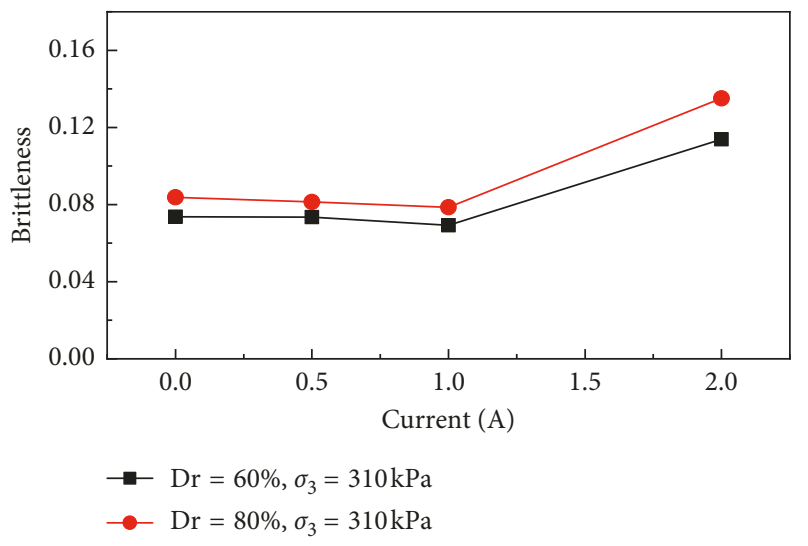

(c)

FIGURE 6: Brittleness index: effect of the magnitude of electromagnetic field on the brittleness index of specimens under (a) $103 \mathrm{kPa}$, (b) $206 \mathrm{kPa}$, and (c) $310 \mathrm{kPa}$.

TABle 4: Brittleness.

\begin{tabular}{|c|c|c|c|c|c|}
\hline$\sigma_{3}(\mathrm{kPa})$ & Sand $(\mathrm{kPa})$ & $\begin{array}{l}\text { Iron-powdered } \\
\text { sand }(\mathrm{kPa})\end{array}$ & $\begin{array}{c}\text { Iron-powdered sand } \\
\text { under } 0.5 \mathrm{~A}(\mathrm{kPa})\end{array}$ & $\begin{array}{c}\text { Iron-powdered sand } \\
\text { under } 1 \mathrm{~A}(\mathrm{kPa})\end{array}$ & $\begin{array}{c}\text { Iron-powdered sand } \\
\text { under } 2 \mathrm{~A}(\mathrm{kPa})\end{array}$ \\
\hline \multicolumn{6}{|c|}{ Relative density at $60 \%$} \\
\hline 103 & 0.09 & 0.07 & 0.11 & 0.13 & 0.14 \\
\hline 206 & 0.09 & 0.08 & 0.08 & 0.09 & 0.08 \\
\hline 310 & 0.09 & 0.07 & 0.07 & 0.07 & 0.11 \\
\hline \multicolumn{6}{|c|}{ Relative density at $80 \%$} \\
\hline 103 & 0.11 & 0.08 & 0.12 & 0.16 & 0.15 \\
\hline 206 & 0.11 & 0.10 & 0.10 & 0.11 & 0.11 \\
\hline 310 & 0.13 & 0.08 & 0.08 & 0.08 & 0.14 \\
\hline
\end{tabular}

TABLE 5: Energy absorption capacity.

\begin{tabular}{|c|c|c|c|c|c|}
\hline$\sigma_{3}(\mathrm{kPa})$ & Sand $(\mathrm{kPa})$ & $\begin{array}{l}\text { Iron-powdered } \\
\text { sand }(\mathrm{kPa})\end{array}$ & $\begin{array}{l}\text { Iron-powdered sand } \\
\text { under } 0.5 \mathrm{~A}(\mathrm{kPa})\end{array}$ & $\begin{array}{c}\text { Iron-powdered sand } \\
\text { under } 1 \mathrm{~A}(\mathrm{kPa})\end{array}$ & $\begin{array}{c}\text { Iron-powdered sand } \\
\text { under } 2 \mathrm{~A}(\mathrm{kPa}) \\
\end{array}$ \\
\hline \multicolumn{6}{|c|}{ Relative density at $60 \%$} \\
\hline 103 & 3173.38 & 3253.88 & 3500.11 & 3518.13 & 3802.56 \\
\hline 206 & 6355.85 & 6453.01 & 6432.52 & 6812.96 & 6773.75 \\
\hline 310 & 8865.79 & 9128.71 & 9585.37 & 9443.23 & 9745.08 \\
\hline \multicolumn{6}{|c|}{ Relative density at $80 \%$} \\
\hline 103 & 3541.93 & 3554.64 & 3788.64 & 3864.91 & 3819.25 \\
\hline 206 & 6349.85 & 7497.74 & 7359.33 & 7959.01 & 7762.73 \\
\hline 310 & 9117.75 & 10255.34 & 10546.79 & 10721.98 & 10820.73 \\
\hline
\end{tabular}




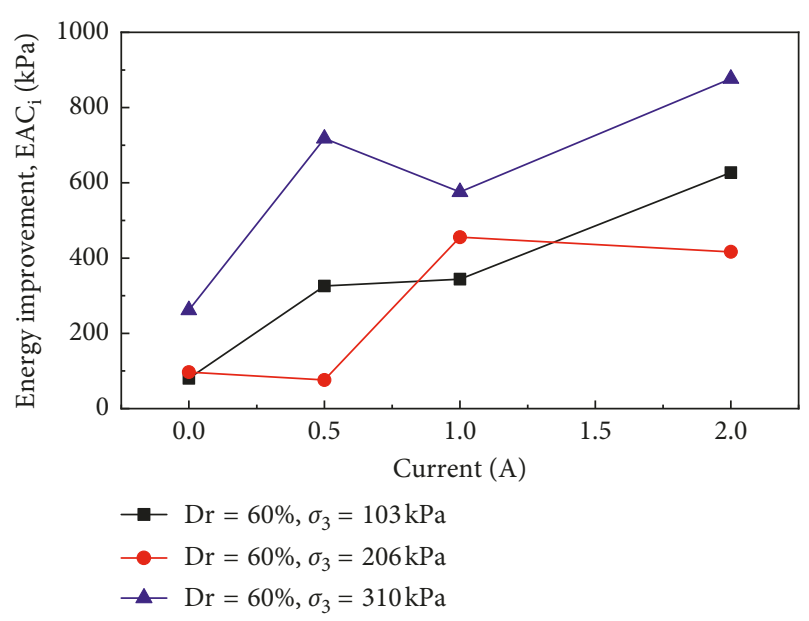

(a)

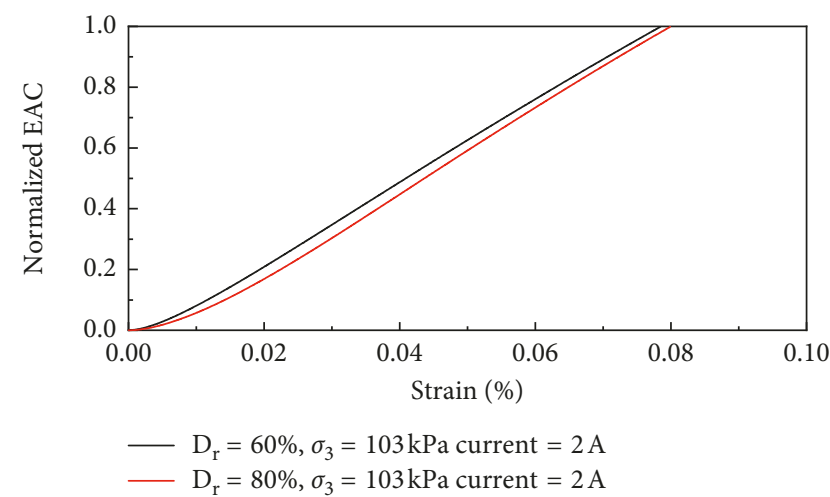

(c)

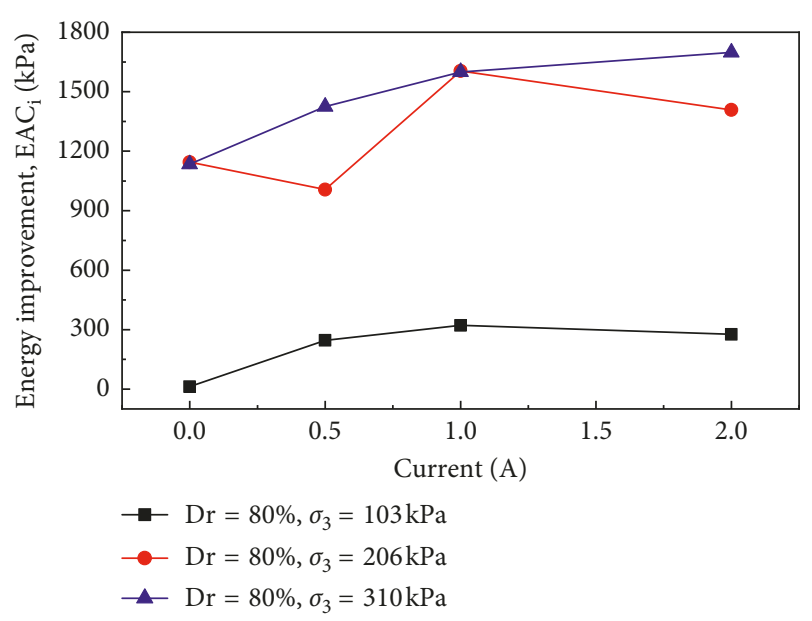

(b)

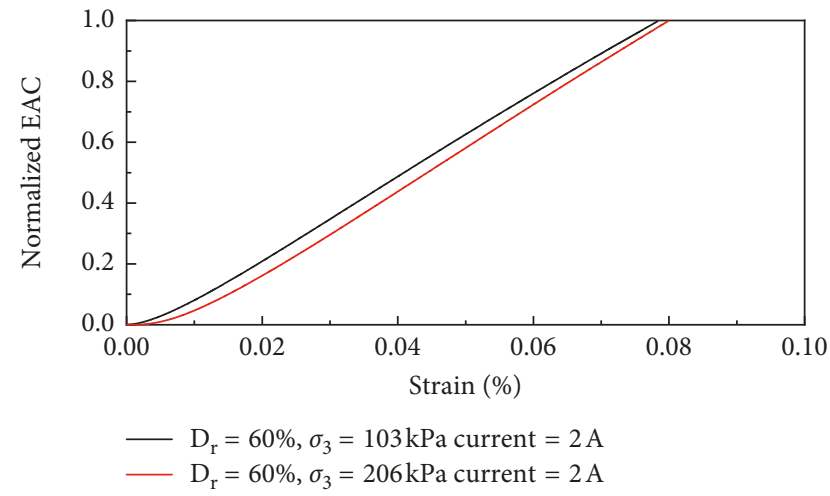

(d)

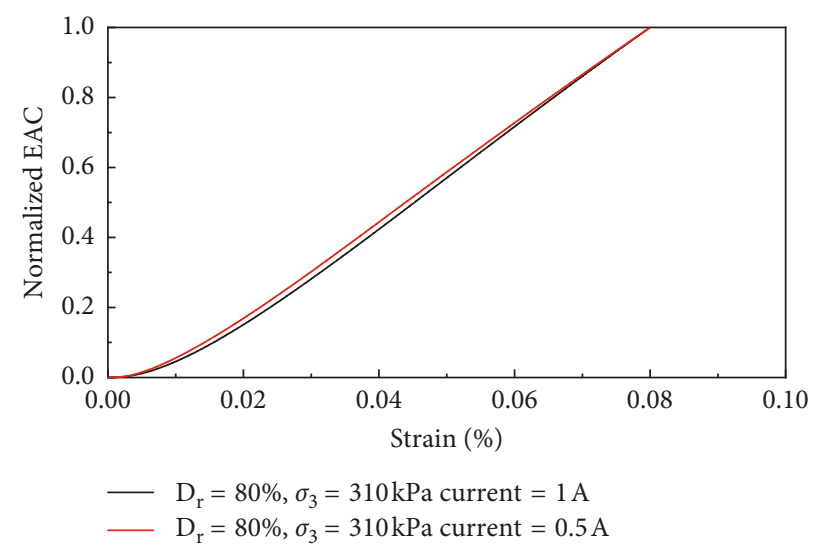

(e)

FiguRE 7: Energy absorption capacity: effect of the magnitude of electromagnetic field on energy absorption capacity improvement of specimens at (a) $60 \%$ relative density and (b) $80 \%$ relative density and effect of (c) relative density, (d) confining pressure, and (e) magnitude of the electromagnetic field on normalized energy absorption capacity.

This problem is simply solved by regressing $q$ on $p$ on the polar planes and rotating $q$ and $p$ axes by an angle $\theta$ (normally $45^{\circ}$ ). Consequently, the $y$-axis is parallel to the data variability direction as shown in Figure 9.

It is solved as follows: first, the abscissa of the center of the Mohr circle and the radius are calculated based on the minor principle stress and major principle stress from the triaxial tests:

$$
\begin{aligned}
& p=\left(\sigma_{1}+\sigma_{3}\right) / 2, \\
& q=\left(\sigma_{1}-\sigma_{3}\right) / 2 .
\end{aligned}
$$

Second, we convert the data set $p-q$ from rectangular coordinates to polar coordinates, which are designated as $\theta$ and $r$. Third, $45^{\circ}$ is added to $\theta$, which gives us $\theta_{r}$. Fourth, convert $\theta_{r}$ and $r$ back to the rectangular plane, which are 


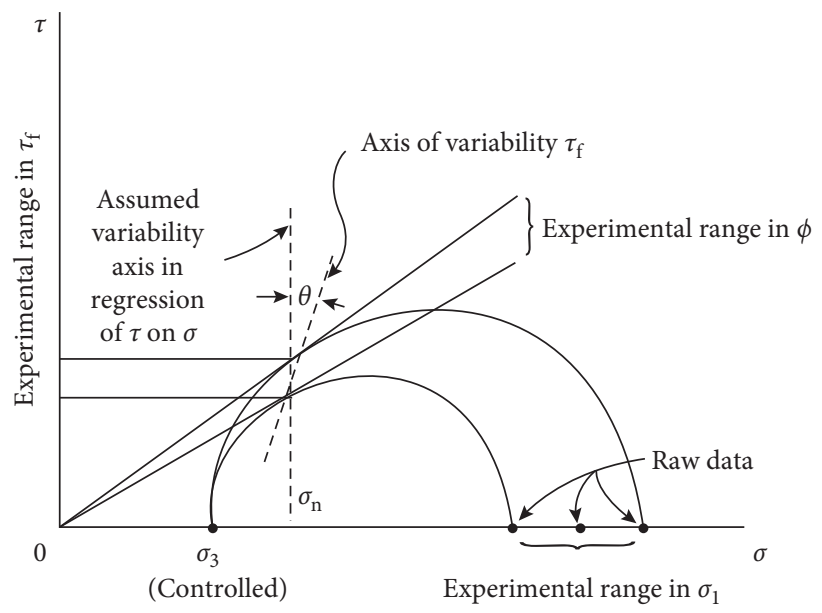

Figure 8: Incorrect regression of $\tau$ on $\sigma$ [40].

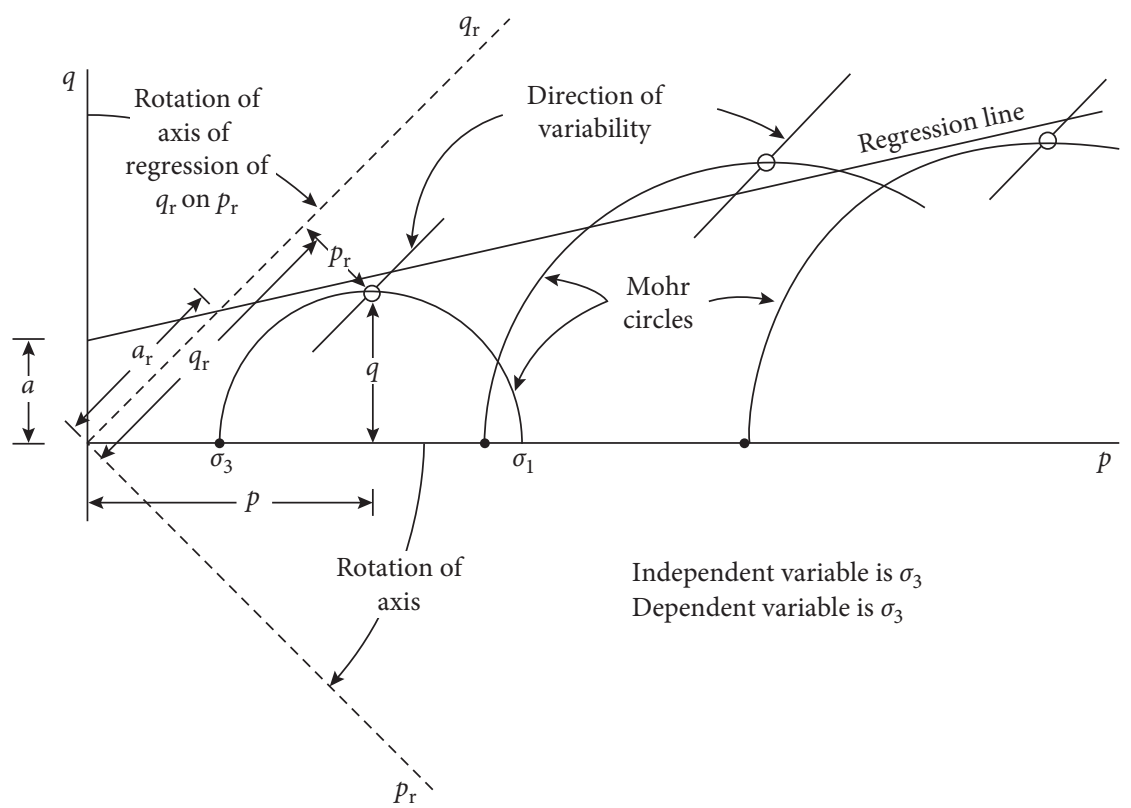

Figure 9: $p-q$ diagram for $q_{\mathrm{r}}$ on $p_{\mathrm{r}}$ after rotation [40].

$p_{r}-q_{r}$ data points. Last, perform regression on $p_{r}-q_{r}$ data, and the slope and intercept of the regression line are termed as $\alpha$ and $a_{r}$, correspondingly. Finally, the following relationships are applied to relate $\alpha$ and $a_{r}$ to friction angle $\phi$ and cohesive coefficient $c$ :

$$
\begin{aligned}
\sin \phi & =\tan \alpha, \\
c & =a / \cos \phi,
\end{aligned}
$$

where

$$
a=a_{r}\left[\frac{\sin (90-\Delta \theta-\alpha)}{\cos \alpha}\right] .
$$

By following the procedure above, the friction angle and the cohesive coefficient can be obtained. The friction angle and the cohesive coefficient are listed in Table 6 . The results of the nonrotated method compared with Handy's method are shown in Figure 10 and Table 6; Handy's method generally agrees with the corresponding test results compared with the nonrotated method.

\section{Conclusions}

The improvement of soil strength by inclusion of iron powder and magnetic field was evaluated in this study. This investigation included the performance on triaxial tests of Ottawa sand and iron-powdered sand under different magnetic fields and development of the stress-strain relationship. A revised Duncan-Chang model was proposed to simulate the strain-softening behavior of specimens. The following main conclusions and observations can be made from this investigation:

(1) The most impressive advantage of iron powder inclusion together with electromagnetic field reinforcement was the improvement of peak strength 
TABLE 6: Friction angle and cohesive coefficient.

\begin{tabular}{|c|c|c|c|c|}
\hline \multirow{2}{*}{ Type of the specimen } & \multicolumn{2}{|c|}{ Friction angle, $\phi\left(^{\circ}\right)$} & \multicolumn{2}{|c|}{ Cohesive coefficient, $c$ (psi) } \\
\hline & Nonrotated method & Rotated method & Nonrotated method & Rotated method \\
\hline Sand at $60 \% D_{\mathrm{r}}$ & 35.082 & 35.080 & 0.004 & 0.001 \\
\hline Iron-powdered sand at $60 \% D_{\mathrm{r}}$ & 35.686 & 35.683 & 0.031 & 0.818 \\
\hline Iron-powdered sand at $60 \% D_{\mathrm{r}}$ and $0.5 \mathrm{~A}$ & 35.799 & 35.785 & 0.220 & 1.322 \\
\hline Iron-powdered sand at $60 \% D_{\mathrm{r}}$ and $1 \mathrm{~A}$ & 36.408 & 36.404 & 0.374 & 1.361 \\
\hline Iron-powdered sand at $60 \% D_{\mathrm{r}}$ and $2 \mathrm{~A}$ & 37.543 & 37.544 & 1.044 & 3.857 \\
\hline Sand at $80 \% D_{\mathrm{r}}$ & 37.413 & 37.415 & 0.005 & -0.0001 \\
\hline Iron-powdered sand at $80 \% D_{\mathrm{r}}$ & 37.608 & 37.581 & 0.372 & 0.573 \\
\hline Iron-powdered sand at $80 \% D_{\mathrm{r}}$ and $0.5 \mathrm{~A}$ & 38.007 & 37.981 & 0.727 & 3.09 \\
\hline Iron-powdered sand at $80 \% D_{\mathrm{r}}$ and $1 \mathrm{~A}$ & 39.276 & 39.167 & 0.738 & 3.104 \\
\hline Iron-powdered sand at $80 \% D_{\mathrm{r}}$ and $2 \mathrm{~A}$ & 38.716 & 39.538 & 0.752 & 3.721 \\
\hline
\end{tabular}

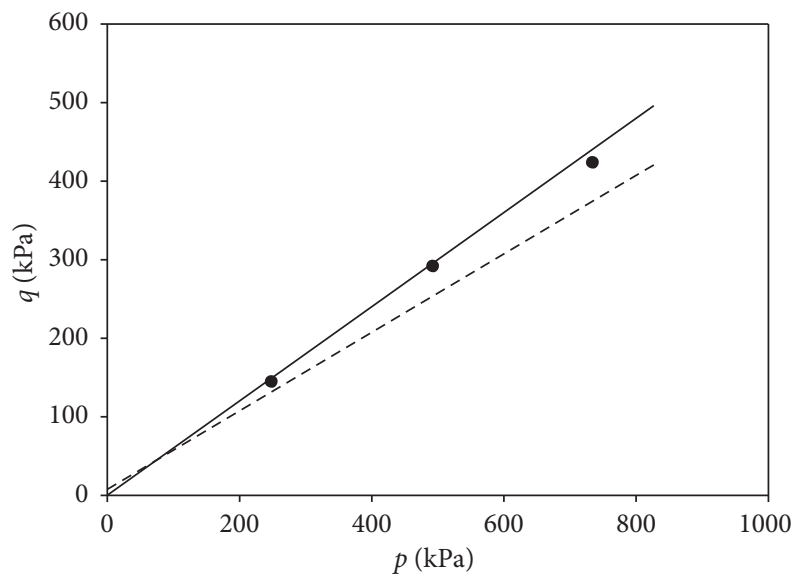

- Data

- Rotated method

- - - Nonrotated method

Figure 10: Sand with iron powder at $60 \%$ relative density under $2 \mathrm{~A}$ current.

and shear strength. The positive impact was more significant at medium to low confining pressure. It is reasonable since the specimens under high confining pressure are already stiff and the effectiveness of iron powder together with the electromagnetic field is less remarkable.

(2) The addition of iron powder to pure sand increased the peak stress, energy absorption, and brittleness. The initial stiffness improved with the addition of iron powder for the specimens at $60 \%$ relative density; however, the initial stiffness of specimens at $80 \%$ relative density was insensitive to the iron powder inclusion. Moreover, the addition of iron powder slightly improved internal friction angle and most importantly introduced the cohesive coefficient to specimens which were zero for pure sand.

(3) By applying the electromagnetic field, the peak stress, energy absorption, friction angle, cohesive coefficient, and strength ratio, the initial stiffness improved with the increase of the electromagnetic field except for the specimens with $80 \%$ relative density and under confining pressure of $310 \mathrm{kPa}$. This is explained by that the specimens with $80 \%$ relative density and under $310 \mathrm{kPa}$ confining pressure are already stiff, and therefore, the improvement is not apparent. In parallel, the brittleness of specimens increased with the increase of magnitude of the electromagnetic field which agrees well with the increase of stiffness.

(4) The initial stiffness of iron-powdered sand was determined by the confining pressure, relative density, iron powder content, and magnitude of the electromagnetic field. Among these controllable testing variables, the confining pressure and stiffness have major impact on the elastic modulus. The effect of the inclusion of iron powder on the elastic modulus was positive for specimens at $60 \%$ relative density and was less obvious on the specimens at $80 \%$ relative density. By applying the electromagnetic field, the initial stiffness improved except for the specimens that were already stiff ( $80 \%$ relative density and under $310 \mathrm{kPa}$ confining pressure). It can be stated that the combination of the inclusion of iron powder and electromagnetic field has great potential in improvement of initial stiffness.

(5) At a relative density of $60 \%$, most of the iron powder was coated around sand particles and few was filled into voids between particles to densify the specimens. Hence, the coating by iron powder reduced the surface friction of iron powder-reinforced specimens in the microscopic view and made the coating soil particles easier to rearrange. As a result, it reduced the initial stiffness and overall brittleness by making specimens easier to deform. However, compared with specimens with a relative density of $60 \%$, specimens at $80 \% D_{\mathrm{r}}$ contain smaller voids and more iron powder. Therefore, except coating around sand particles, iron powder filled most of the voids which densified iron powder-reinforced specimens. Moreover, the densification effect from filling voids by iron powder dominates over the coating effect around particles; as a result, the strength improvement was more pronounced at $80 \%$ relative density.

We conclude that this innovative method of autoadaptive media has the potential to be a valuable means of 
strengthening the soil by temporary solidification. This characteristic is applicable in earthquake engineering by sensing and intentionally mitigating the external disturbance. However, the development and evaluation of this investigation still require intensive laboratory tests. The challenge in practice is mixing the iron powder with sand uniformly in the field and effectively placing a magnetic field on-site.

\section{Data Availability}

The data sets generated in the current study are available from the corresponding author on reasonable request.

\section{Conflicts of Interest}

The authors declare that they have no conflicts of interest.

\section{Acknowledgments}

This research was supported by the National Natural Science Foundation of China (Nos. 51809231 and 51808490) and "the Fundamental Research Funds for the Central Universities" (No. 2018FZA4016).

\section{References}

[1] D. H. Gray and T. Al-Refeai, "Behavior of fabric-versus fiberreinforced sand," Journal of Geotechnical Engineering, vol. 112, no. 8, pp. 804-820, 1986.

[2] M. Hoshiya and J. N. Mandal, "Metallic powders in reinforced earth," Journal of Geotechnical Engineering, vol. 110, no. 10, pp. 1507-1511, 1984.

[3] H. A. D. Kirsten, "Equivalence of mesh- and fibre- reinforced shotcrete at large deflections," Canadian Geotechnical Journal, vol. 30, no. 3, pp. 418-440, 1993.

[4] M. H. Maher and D. H. Gray, "Static response of sands reinforced with randomly distributed fibers," Journal of Geotechnical Engineering, vol. 114, no. 11, pp. 1661-1677, 1990.

[5] S. Teixeira, B. Bueno, and J. Zornberg, "Pullout resistance of individual Longitudinal and transverse geogrid ribs," Journal of Geotechnical and Geoenvironmental Engineering, vol. 133, no. 1, pp. 37-50, 2007.

[6] C.-S. Tang, B. Shi, Y.-J. Cui, C. Liu, and K. Gu, "Desiccation cracking behavior of polypropylene fiber-reinforced clayey soil," Canadian Geotechnical Journal, vol. 49, no. 9, pp. 1088-1101, 2012.

[7] I. L. Casagrande, "Electro-osmosis in soils," Géotechnique, vol. 1, no. 3, pp. 159-177, 1949.

[8] Q. Tang, F. Gu, Y. F. Gao, T. Inui, and T. Katsumi, "Desorption characteristics of $\mathrm{Cr}(\mathrm{III}), \mathrm{Mn}$ (II) and $\mathrm{Ni}$ (II) in contaminated soil using citric acid and citric acid containing wastewater," Soils and Foundations (JGS), vol. 58, pp. 50-64, 2018.

[9] N. D.. Quang and J. C. Chai, "Permeability of lime-and cement-treated clayey soils," Canadian Geotechnical Journal, vol. 52, no. 9, pp. 1221-1227, 2015.

[10] L. Yang and R. D. Woods, "Shear stiffness modeling of cemented clay," Canadian Geotechnical Journal, vol. 52, pp. 152-166, 2014.
[11] Y. Yi, M. Liska, C. Unluer, and A. Al-Tabbaa, "Carbonating magnesia for soil stabilization," Canadian Geotechnical Journal, vol. 50, no. 8, pp. 899-905, 2013.

[12] J. T. Holden, "Improved thermal computations for artificially frozen shaft excavations," Journal of Geotechnical and Geoenvironmental Engineering, vol. 123, no. 8, pp. 696-701, 1997.

[13] R. C. Joshi, G.. Achari, D. Horsfield, and T. S. Nagaraj, "Effect of heat treatment on strength of clays," Journal of geotechnical engineering, vol. 129, no. 6, pp. 1080-1088, 1994.

[14] S. B. Choi, "Vibration control of flexible structures using ER dampers," Journal of Dynamic Systems, Measurement and Control Transaction of ASME, vol. 121, pp. 134-138, 1999.

[15] S. J. Dyke, B. F. Spencer, M. K. Sain, and J. D. Calrson, "Anex perimental study of MR dampers on seismic protection," Smart Materials and Structures, vol. 7, pp. 693-703, 1998.

[16] T. Pranoto, K. Nagaya, and A. Hosoda, "Vibration suppression of plate using linear MR fluid passive damper," Journal of Sound and Vibration, vol. 276, pp. 919-932, 2004.

[17] R. D. Hryciw and E. Susila, "Temporary solidification of coarse grained soil by magnetorheological fluids," in Proceedings of Soil dynamics symposium in honor of Professor Richard D. Woods, GSP, vol. 134, pp. 1-14, 2005.

[18] S. Boussetta, M. Bouassida, and M. Zouabi, "Numerical behavior of reinforced soil by rigid inclusion," in Proceedings of Geo-China International Conference, pp. 225-232, 2016.

[19] C. Li and J. G. Zornberg, "Mobilization of reinforcement forces in fiber-reinforce soil," Journal of Geotechnical and Geoenvironmental Engineering, vol. 139, no. 1, pp. 107-115, 2012.

[20] COMSOL, Comsol Multiphysics 4.3a (Computer software), COMSOL, Stockholm, Sweden.

[21] Q. Tang, F. Gu, Y. Zhang, Y. Zhang, and J. Mo, "Impact of biological clogging on the barrier performance of landfill liners," Journal of Environmental Management, vol. 222, pp. 44-53, 2018.

[22] E. B. Burwell, "Cement and clay grouting of foundations. Practice of the corps of engineering," ASCE Soil Mechanics and Foundations Division, vol. 84, pp. 1551/1 -1551/22, 1958.

[23] ASTM, Standard Test Methods For Maximum Index Density And Unit Weight Of Soils Using A Vibratory Table. D4253, ASTM International, West Conshohocken, PA, USA, 2006.

[24] ASTM, Standard Test Methods For Minimum Index Density And Unit Weight Of Soils And Calculation Of Relative Density. D4254, ASTM International, West Conshohocken, PA, USA, 2006.

[25] ASTM, Standard Test Methods For Unconsolidated-Undrained Triaxial Compression Test On Cohesive Soils. D2850-15, ASTM International, West Conshohocken, PA, USA, 2006.

[26] J. E. Bowels, Engineering Properties Of Soils And Their Measurement, McGraw-Hill book Company, New York, NY, USA, 1970.

[27] K. H. Head, Manual of Soil Laboratory Testing, Pentech Press, London, UK, 2nd edition, 1994.

[28] F. Tatsuoka, S. Shibuya, and R. Kuwano, Advanced Laboratory Stress-Strain Testing of Geomaterials, A. A. Balkema publishers, Tokyo, Japan, 2001.

[29] J. M. Duncan and C. Y. Chang, "Nonlinear analysis of stress and strain in soils," Journal of the Soil Mechanics and Foundations Division, ASCE, vol. 96, no. SM5, pp. 1629-1653, 1970. 
[30] H. Altenbach, G. B. Stoychev, and K. N. Tushtev, "On elastoplastic deformation of grey cast iron," International Journal of Plasticity, vol. 17, no. 5, pp. 719-736, 2000.

[31] R. O. Davis and A. P. Selvadurai, Elasticity and Geomecanics, Cambridge University Press, USA, 1996.

[32] R. O. Davis and A. P. S. Selvadurai, Plasiticity and Geomechanics, Cambridge University Press, UK, 2002.

[33] P. V. Lade, "Elastic-plastic stress-strain theory for cohesionless soil with curved yield surfaces," International journal of solids and structures, vol. 13, no. 11, pp. 1019-1035, 1977.

[34] P. V. Lade and J. M. Duncan, "Elastoplastic stress-strain theory for cohesionless soil," Journal of Geotechnical Engineering, vol. 101, pp. 1037-1053, 1975.

[35] T. W. Lambe and R. V. Whitman, Soil Mechanics, John Wiley \& Sons, Inc, New York, NY, USA, 1969.

[36] H. Matsuoka and T. Nakai, "Stress-deformation and strength characteristics of soil under three different principal stress," Proceedings of the Japan Society of Civil Engineers, vol. 1974, no. 232, pp. 59-70, 1974.

[37] K. H. Roscoe and A. N. Schofield, "Mechanical behavior of an idealized "wet clay"," in Proceedings of 2 nd European Conference on Soil Mechanics and Foundation Engineering, vol. 1, pp. 47-54, Wiesbaden, Germany, 1963.

[38] N. C. Consoli, J. P. Montardo, P. D. Marques Prietto, and G. Savitri Pasa, "Engineering behavior of a sand reinforced with plastic waste," Journal of Geotechnical and Geoenvironmental Engineering, vol. 128, no. 6, pp. 462-472, 2002.

[39] ASTM, Standard test method for flexural toughness and firstcrack strength of fibre-reinforced concrete (Using beam with third-point loading). C1018, ASTM international, West Conshohocken, PA, USA, 1997.

[40] R. L. Handy, "Linearizing tri-axial test failure envelopes," Geotechnical Testing Journal, vol. 4, no. 4, pp. 188-191, 1981. 


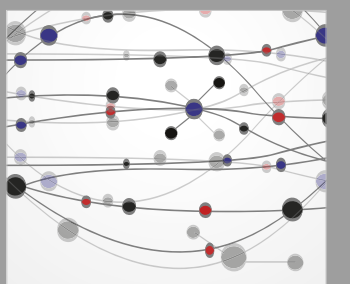

The Scientific World Journal
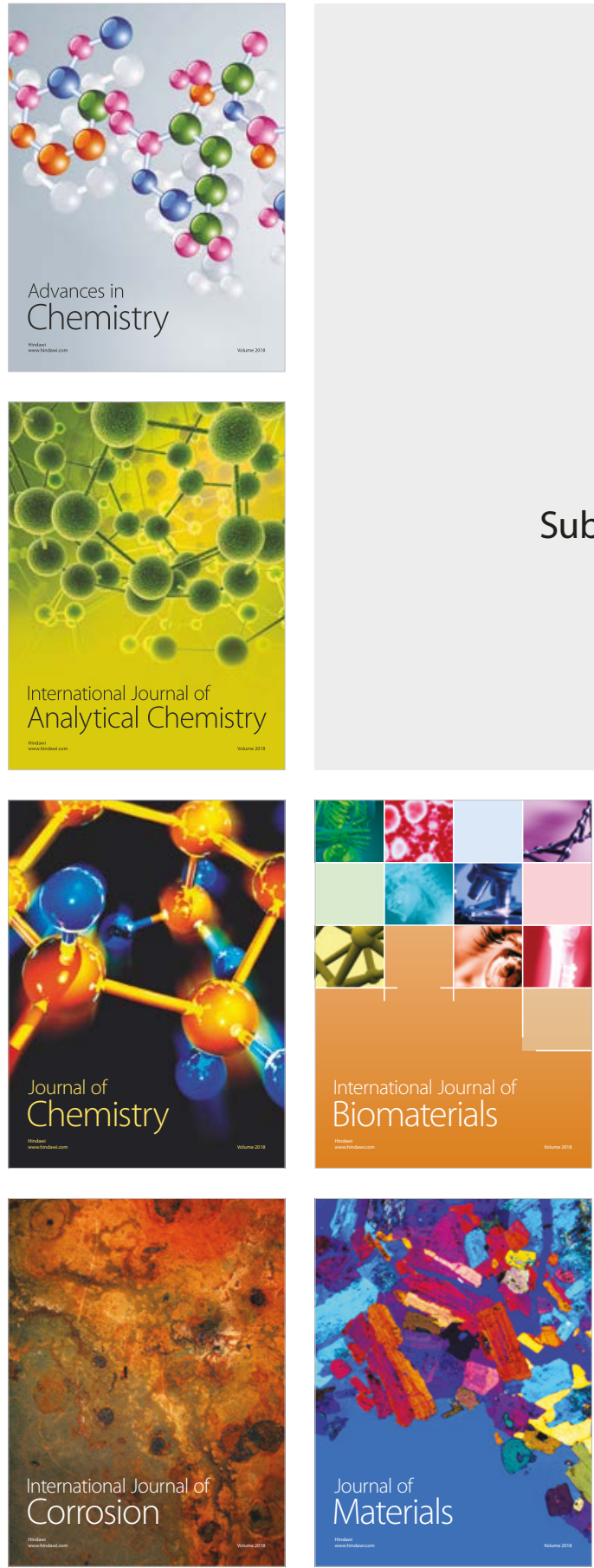

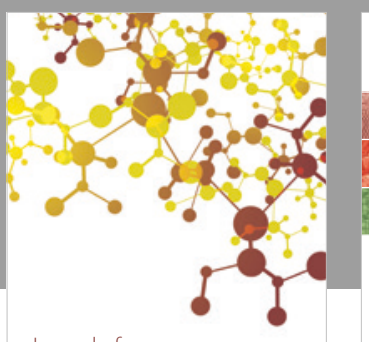

Journal of

Applied Chemistry
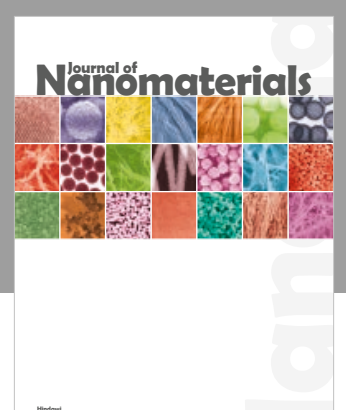

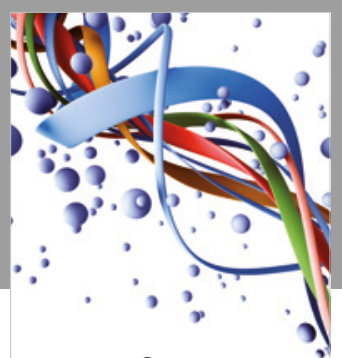

Scientifica

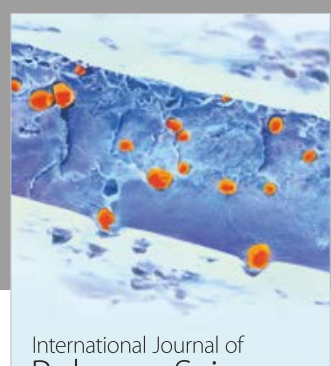

Polymer Science

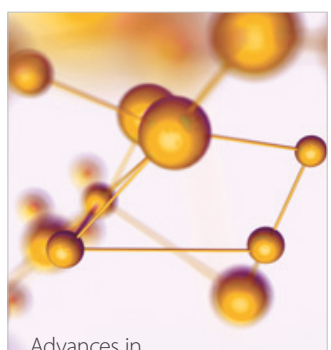

Physical Chemistry
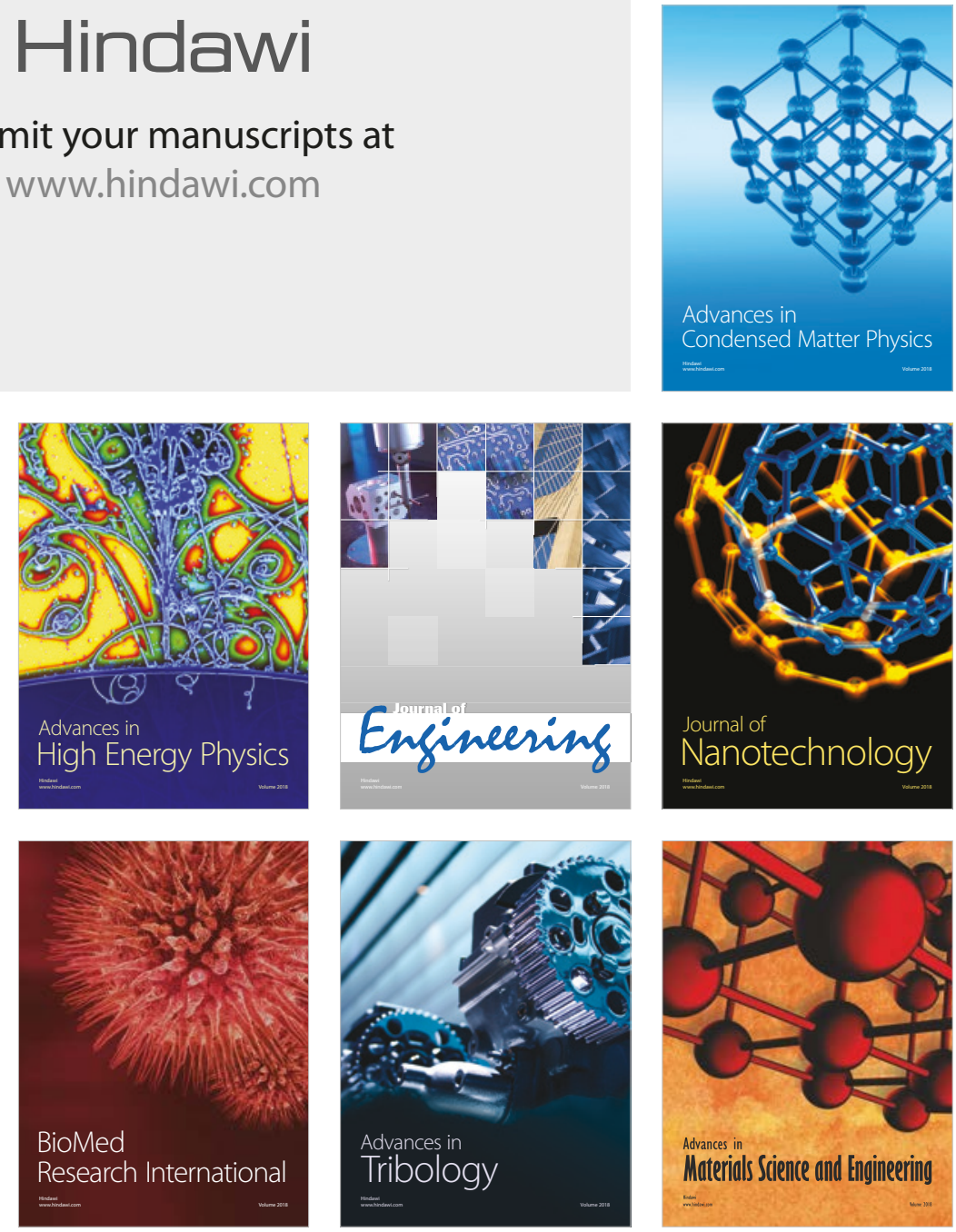